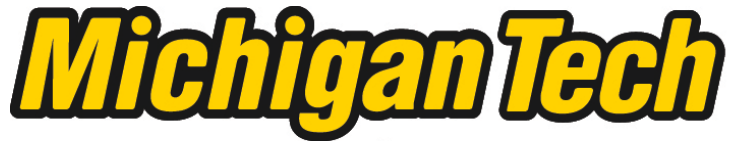 \\ Michigan Technological University Create the Future Digital Commons @ Michigan Tech
}

\section{Augmenting the piezoelectric in portland cement paste for structural health monitoring applications}

Benjamin A. Roskoskey

Michigan Technological University

Follow this and additional works at: https://digitalcommons.mtu.edu/etds

Part of the Civil and Environmental Engineering Commons

Copyright 2012 Benjamin A. Roskoskey

\section{Recommended Citation}

Roskoskey, Benjamin A., "Augmenting the piezoelectric in portland cement paste for structural health monitoring applications", Master's report, Michigan Technological University, 2012.

https://doi.org/10.37099/mtu.dc.etds/501

Follow this and additional works at: https://digitalcommons.mtu.edu/etds

Part of the Civil and Environmental Engineering Commons 


\title{
AUGMENTING THE PIEZOELECTRIC EFFECT IN PORTLAND CEMENT PASTE FOR STRUCTURAL HEALTH MONITORING APPLICATIONS
}

By

Benjamin A. Roskoskey

\begin{abstract}
A REPORT
Submitted in partial fulfillment of the requirements for the degree of MASTER OF SCIENCE

Civil Engineering
\end{abstract}

MICHIGAN TECHNOLOGICAL UNIVERSITY

2012

(C) 2012 Benjamin A. Roskoskey 
This report, "Increasing the Piezoelectric Effect in Cement Paste for Structural Health Monitoring Applications," is hereby approved in partial fulfillment of the requirements for the Degree of MASTER OF SCIENCE IN CIVIL ENGINEERING.

Civil and Environmental Engineering

Signatures:

Report Advisor

Dr. R. Andrew Swartz

Committee Member

Dr. Stanley J. Vitton

Committee Member

Dr. Bo Chen

Department Chair

Dr. David W. Hand

Date 


\begin{abstract}
This report details the outcomes of a study designed to investigate the piezoelectric properties of Portland cement paste for its possible applications in structural health monitoring. Specifically, this study provides insights into the effects on piezoelectric properties of hardened cement paste from the application of an electric field during the curing process. As part of the reporting of this study, the state of the art in structural health monitoring is reviewed. In this study it is demonstrated that application of an electric field using a spatially-coarse array of electrodes to cure cement paste was not effective in increasing the magnitude of the piezoelectric coupling, but did increase repeatability of the piezoelectric response of the hardened material.
\end{abstract}




\section{Acknowledgements}

I would like to thank my advisor Dr. Andrew Swartz for all of his invaluable knowledge and support, without him this project would have been a failure. I would also like to thank the employees of Benedict Lab, especially Kiko, for all of their help and guidance with sample preparation and testing. I owe much to my parents; they have always encouraged and consoled me. Last but not least, I'd like to extend a big thank-you to my fiancée, Katie. She has spent much time keeping me on track and cheering me up when I felt that all hope was lost. 


\section{Contents`}

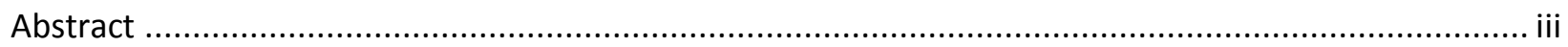

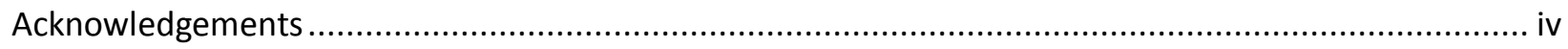

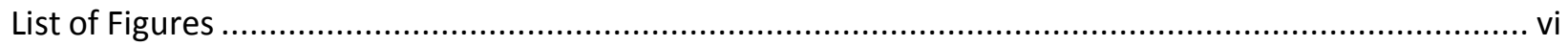

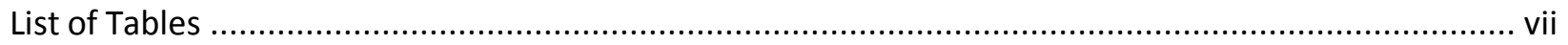

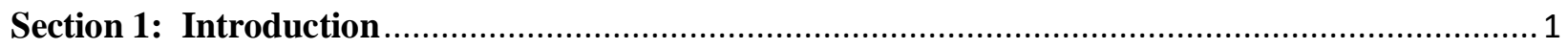

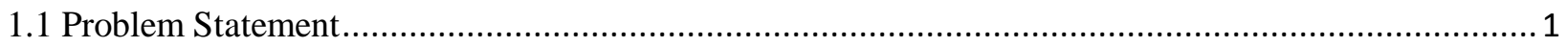

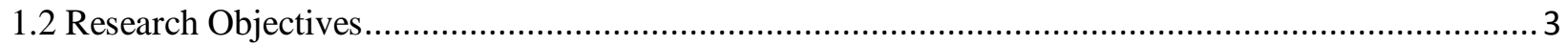

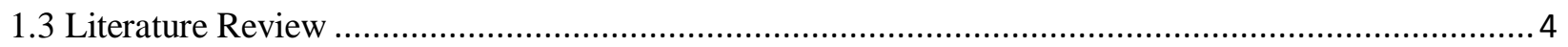

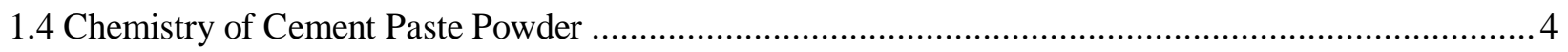

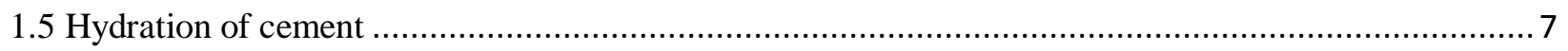

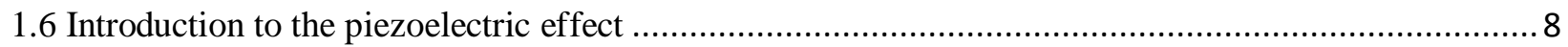

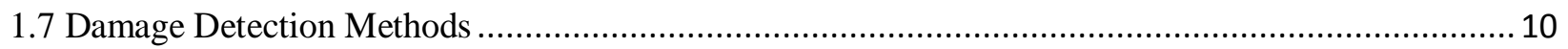

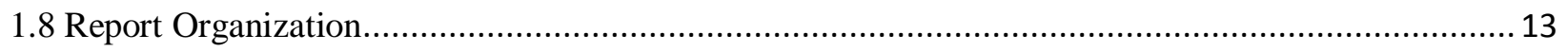

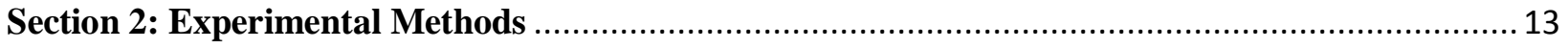

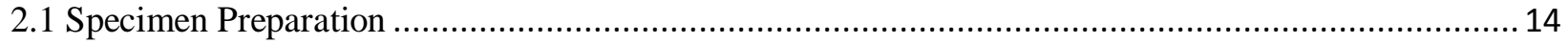

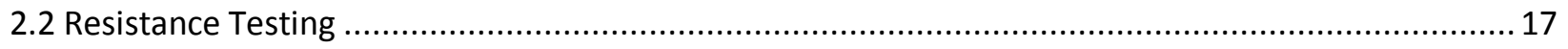

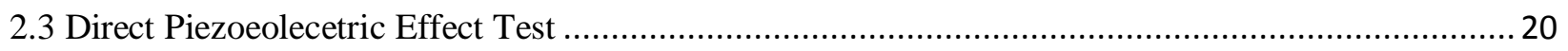

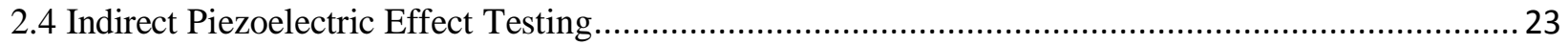

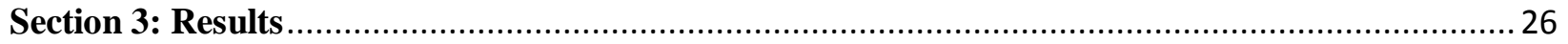

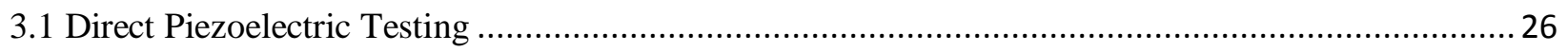

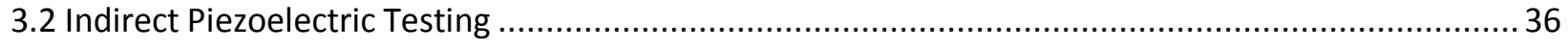

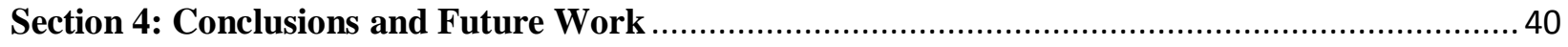

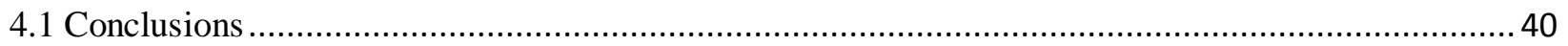

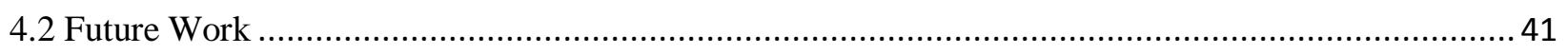

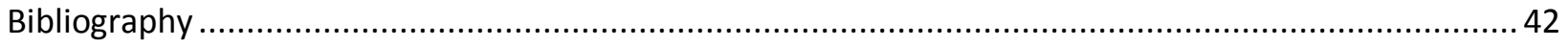




\section{List of Figures}

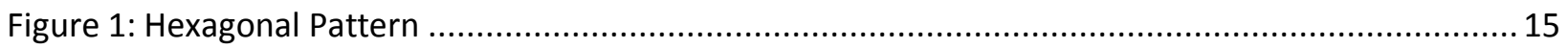

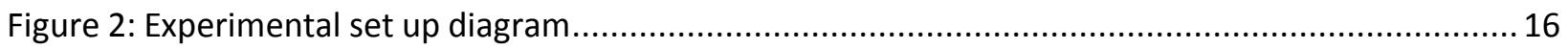

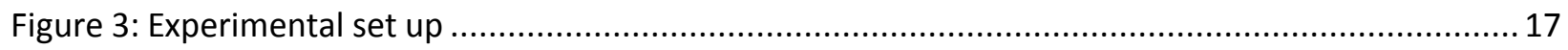

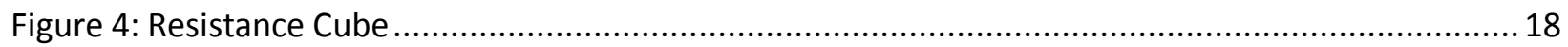

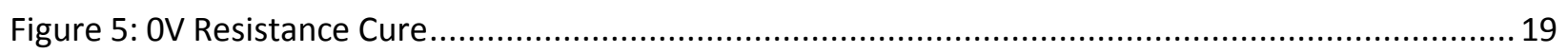

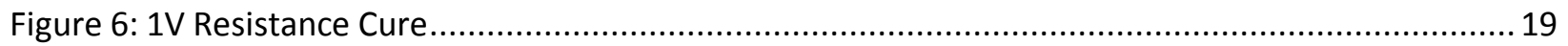

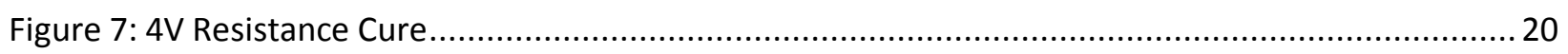

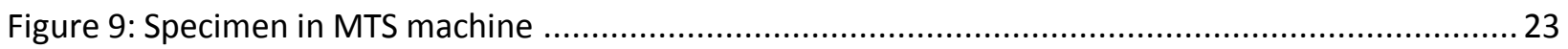

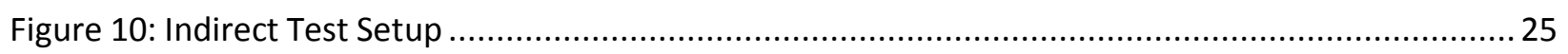

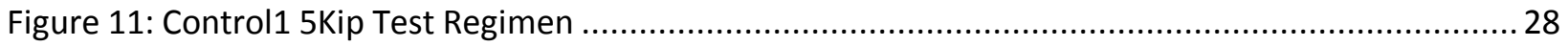

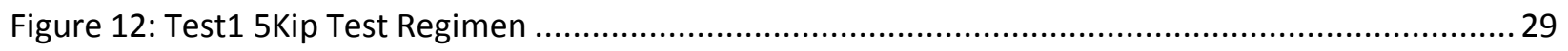

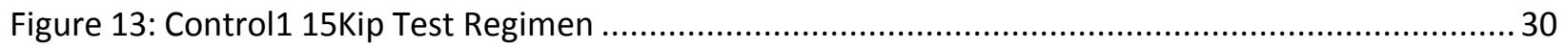

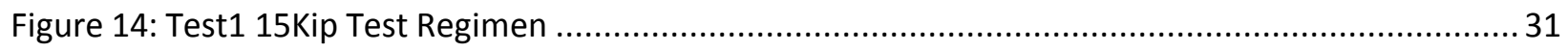

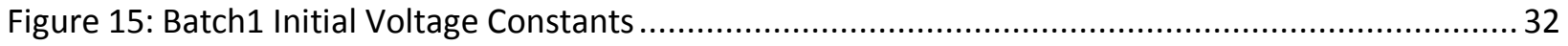

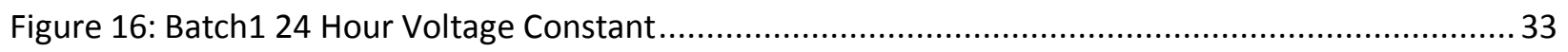

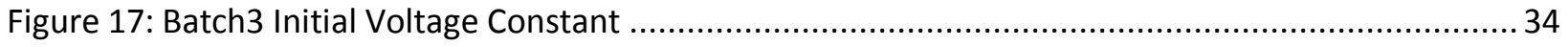

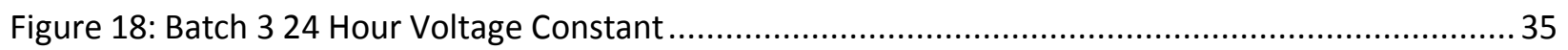

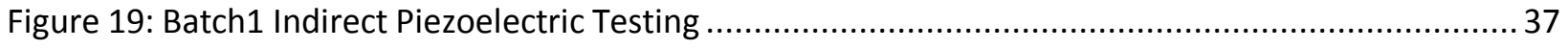

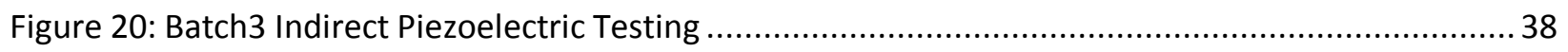

Figure 21: Batch3 Indirect Piezoelectric Testing After Damage ....................................................... 39 


\section{List of Tables}

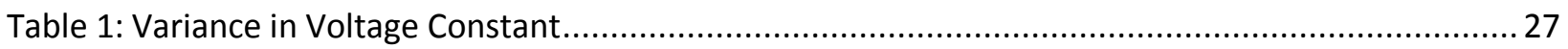




\section{Section 1: Introduction}

With the degrading state of infrastructure in the United States, the ability to detect and analyze damage in concrete structures is becoming increasingly important to manage these important assets. One important technique for structural health monitoring (SHM) is the analysis of structural vibrations and their changes over time, changes that may be indicative of damage. High-frequency, local vibrations excited using piezoelectric transducers have proven effective in detecting damage in civil, mechanical and aerospace structures.

\subsection{Problem Statement}

Civil engineering structures play a very important role in society. People live and work in buildings, utilize roads and bridges for daily transportation, and rely on dams and power plants to provide reliable electricity to run their everyday lives. Over time, corrosion and fatigue due to elemental effects and applied loads can lead to the degradation of these structures. External damage and defects can be spotted by routine inspections, but internal damage can be harder to identify and locate and, as a result, can be more threatening to the lifespan and safety of a structure and its users. Furthermore, inspections can be time-consuming and costly, straining limited management budgets and may not be performed as often as necessary for proper conditional assessment. This is why SHM has become so important recently. 
SHM, the process of implementing a damage detection and characterization strategy for structures [1], has been attracting much attention in recent years. SHM usually utilizes a network of sensors, actuators and control mechanisms to sense a stimulus, respond to the stimulus in a predetermined manner and extent in a short appropriate time, and depending on the type of system used may then revert the structure back to its original state as soon as the stimulus is removed. Commonly used sensors and actuators used in SHM include piezoelectric patches, which take advantage of the piezoelectric effect to provide active sensing, a system by which the SHM sensor network provides its own excitation signal to generate signals.

The piezoelectric effect is the mechanism that couples the electric and strain domains in some crystalline solids, minerals, and biological materials such as bones and some DNA proteins [2]. When strained dynamically, piezoelectric materials will give off a current based on their sensitivity constant, defined as volts produced per unit of strain $(V / \mu)$. Piezoelectric materials also display the reverse piezoelectric effect; they will have a change in their size when a current is applied to them [3]. 
The purpose of this research project is to explore the use of cement paste as the sole means of SHM; a concept that may help to minimize the degradation caused by embedded sensors and ultimately decrease the cost of maintaining and monitoring a structure. Cement paste itself is a weakly piezoelectric material due to its crystalline structure [4]. Cement paste's piezoelectric coupling coefficient is two orders less than that of standard piezoelectric patches $\left(3.0 \times 10^{-13} \mathrm{~m} / \mathrm{V}\right.$ for cement paste vs. $1.4 \times 10^{-11} \mathrm{~m} / \mathrm{V}$ for lead zirconatotitanate) [4]. This weak coupling between changing electric field and changing strain results in poor generation of mechanical strains or electrical signals should cement paste be used as an active sensor. While it is, of course, possible to simply apply transducers made from lead zirconate titanate to a concrete structure for active sensing, there are cost benefits to using the composite matrix material itself as the transducer material, plus the environmental impact is lessened due to the absence of lead used for monitoring. Therefore, it would be advantageous to increase the piezoelectric coupling coefficient in cement paste as well as understand its piezoelectric properties in more detail.

\subsection{Research Objectives}

The primary focus of this research was to evaluate the ability to increase the piezoelectric coupling coefficient in cement paste by curing it under an electrical current. Additional goals included trying to make the coupling coefficient constant (not dependent on applied loads) and repeatable (constant through many loading cycles) as well as seeing what changes curing under an electrical current would have on the strength of the cement paste. 


\subsection{Literature Review}

This literature review discusses the general background, parameters, and applications of impedance-based SHM approaches

\subsection{Chemistry of Cement Paste Powder}

ASTM 150 defines Portland cement as "hydraulic cement (cement that not only hardens by reacting with water but also forms a water-resistant product) produced by pulverizing clinkers consisting essentially of hydraulic calcium silicates, usually containing one or more of the forms

of calcium sulfate as an inter-ground addition" [5]. Most cement powders have four oxides that make up about ninety percent of them by weight. Those four oxides are lime $(\mathrm{CaO})$, silica $\left(\mathrm{SiO}_{2}\right)$, alumina $\left(\mathrm{Al}_{2} \mathrm{O}_{3}\right)$, and iron oxide $\left(\mathrm{Fe}_{2} \mathrm{O}_{3}\right)$ and are referred to as the 'major oxides' [6]. The remainder of the cement consists of magnesia $(\mathrm{MgO})$, alkali oxides $\left(\mathrm{Na}_{2} \mathrm{O}\right.$ and $\left.\mathrm{K}_{2} \mathrm{O}\right)$, titania $\left(\mathrm{TiO}_{2}\right)$, phosphorus pentoxide $\left(\mathrm{P}_{2} \mathrm{O}_{5}\right)$, and gypsum. These are referred to as the 'minor constituants'. The gypsum is added during grinding of the clinker to help regulate the setting time of the cement [7].

Most modern cements have very high lime content and their composition falls in the area of Portland cement with a lime content exceeding sixty-five percent [7]. Cements classified as Portland cement whose lime content is below sixty-five percent are slow to harden. On the high- 
side, the maximum lime content is limited by the desire to avoid free lime in the cement. Free (uncombined) lime occurs when the materials used in the manufacturing process of cement contain more lime then can combine with the three main acidic oxides $\mathrm{SiO}_{2}, \mathrm{Al}_{2} \mathrm{O}_{3}$, and $\mathrm{Fe}_{2} \mathrm{O}_{3}$. Free lime can also occur when lime has not fully reacted with the acidic oxides by the time the clinkering process has been completed.

The iron oxide and alumina, acting as a flux, help to lower the burning temperature of the cement [8]. The minimum amounts for these oxides is not based on any composition requirement, but rather to help avoid the difficulties associated with very high clinkering temperatures. The maximum amount for these two oxides is determined by the need to limit how quick the cement sets. Cements who have a lower than $1.5 \mathrm{SiO}_{2} /\left(\mathrm{Al}_{2} \mathrm{O}_{3}+\mathrm{Fe}_{2} \mathrm{O}_{3}\right)$ ratio begin to show rapid setting which can no longer be controlled by the addition of gypsum [7].

The four major components of Portland cement clinker (composed of the four major oxides) are: tricalcium silicate $\left(3 \mathrm{CaO} * \mathrm{SiO}_{2}\right)$, dicalcium silicate $\left(2 \mathrm{CaO} * \mathrm{SiO}_{2}\right)$, tricalcium aluminate $\left(3 \mathrm{CaO} * \mathrm{Al}_{2} \mathrm{O}_{3}\right)$, and tetracalcium aluminoferrite $\left(4 \mathrm{CaO}^{2} \mathrm{FeO}_{2} * \mathrm{Al}_{2} \mathrm{O}_{3}\right)$.

Tricalcium silicate is unstable below $1250^{\circ} \mathrm{C}$ and breaks down into $\mathrm{C}_{2} \mathrm{~S}$ and $\mathrm{CaO}$. The breakdown is very slow and below $700^{\circ} \mathrm{C}$ tricalcium silicate exists indefinitely. Its properties are similar to those of Portland cement. It sets within a few hours of being introduced to water and the paste formed hardens within a few hours. The hardened paste gains most of its strength during the first week and its final compressive strength reaches the order of a few tens $\mathrm{N} / \mathrm{mm}^{2}$. 
The heat of hydration for tricalcium silicate is about $500 \mathrm{~J} / \mathrm{g}$ and it makes up between $35 \%$ and $55 \%$ of Portland cement by weight.

There are four forms of dicalcium silicate: alpha, alpha-prime, beta, and gamma [7]. Beta dicalcium silicate is the only form of the four that possesses cementive properties. Pure beta dicalcium silicate inverts to the gamma form once it cools below $520^{\circ} \mathrm{C}$. Impurities, however, affect the rate of inversion and can delay or restrain it indefinitely. The effect that impurities have on dicalcium silicate explains why the beta form is found in Portland cement and why it is stable at room temperature. Dicalcium silicate hardened paste takes weeks and months to reach its full compressive strength. The final compressive strength, which can range from $10 \mathrm{~N} / \mathrm{mm}^{2}$ to being as strong as tricalcium silicate, depends on which type of material is used to stabilize the dicalcium silicate into its beta form. The heat of hydration for beta dicalcium silicate is about $250 \mathrm{~J} / \mathrm{g}$ and make up between $15 \%$ to $35 \%$ of Portland cement by weight.

Tricalcium aluminate reacts with water almost instantaneously when in its pure form and releases about $850 \mathrm{~J} / \mathrm{g}$ of heat. Adding $15 \%$ gypsum helps to regulate normal setting speeds. It gains most of its strength in about a day or two and its ultimate strength is only that of a few $\mathrm{N} / \mathrm{mm}^{2}$. Tricalcium aluminate is not regarded as a hydraulic cement because it disintegrates when in water. It makes up between $7 \%$ and $15 \%$ of Portland cement by weight.

Tetracalcium aluminoferrite reacts with water very rapidly and sets in minutes. It has a very low strength and a heat of hydration around $420 \mathrm{~J} / \mathrm{g}$. It makes up between $5 \%$ and $10 \%$ of Portland cement by weight. 


\subsection{Hydration of cement}

In the presence of water, the major oxides form products of hydration and become a firm and hard mass which is the hydrated cement paste. There are two ways in which the oxides react with water, hydrolysis and hydration. Hydrolysis is the rupture of chemical bonds by the addition of water. Usually one part of the parent molecule will gain a hydrogen ion $\left(\mathrm{H}^{+}\right)$from the split water molecule while the other portion of the parent molecule will gain the hydroxyl group $\left(\mathrm{OH}^{-}\right)$from the water molecule. Essentially an acid and a base are formed. With hydration, a direct addition of some water molecules takes place to the crystal structure of a mineral and usually creates a new mineral called a hydrate. The reactants dissolve and produce ions in solution [7]. The ions then combine and the products precipitate out. Due to the presence of ionic bonding and moisture in cement, electric dipoles are present [4]. Piezoelectricity relates to the dielectric behavior, and specifically the static dielectric constant that is a material property relating to the electric dipole moment per unit volume.

This study hypothesizes that by being cured under a current, the ions in cement paste will be drawn towards the curing source of their opposite charge (i.e. positive ions to the negative charge source, negative ions to the positive charge source). This should cause ion voids in the areas between the applied voltages which will, in turn, increase the electrical resistance of the paste due to the absence of electrical paths. 


\subsection{Introduction to the piezoelectric effect}

The piezoelectric effect is the linear electromechanical interaction between the mechanical and the electrical state in crystalline materials with no inversion symmetry [3]. All piezoelectric materials display both the direct and indirect piezoelectric effect. When acting in the 'direct' manner, piezoelectric materials will produce an electrical charge when mechanically stressed. In the 'indirect' manner, a mechanical strain is produced when the material is introduced to an electric field.

Piezoelectric sensors are advantageous because they can be used for both actuating and sensing, so only one type of sensor needs to be used throughout a member or a structure. This dual sensing/actualing aspect of these sensors also allows for signals to be sent in each direction between sensors, allotting for half as many total gauges as a traditional monitoring system made up of pure sensors and pure actuators. The most common piezoelectric sensors used are lead zirconate titanate (PZT) patches [9].

Usually strain gauges are embedded in a member in order to check for the effects of degradation over time which allows for accurate measurements of the health of the structure, but can have some drawbacks. By being embedded in the concrete the gauges can actually cause degradation. This damage is due to the fact that the gauges and concrete have different modulus of elasticity and different coefficients of thermal expansion. When strained by loads or temperature 
differences the materials expand and contract at different rates, which can cause cracking and other unwanted structural damage. Any water remaining from the hydration process can also cause corrosion to internal sensors. The best way to avoid this damage is to use external piezoelectric patches to measure the health of a structure.

A network of embedded gauges also greatly increases the cost of building and maintaining a structure. Embedded strain gauges typically cost over one hundred dollars each and are only able to monitor a small area of concrete (i.e. that which it is in direct contact with). This limitation means that they must be either placed along the entire length of a member or placed only at the locations that have the largest expected strain calculated using theoretical techniques. The first placement increases the overall cost of the structure linearly by requiring a set amount of gauges per unit length of the structure. The second placement has the drawback of only being able to monitor the theoretical locations of maximum strain and can miss damage caused at other locations based on uneven loading and environmental effects (i.e. freeze/thaw cycle, wind damage, earthquake damage, etc.). Both can increase the chances of environmental degradation due to the outgoing wires needed to gather measurements. These wires penetrate the outer layer of the structural members and, even with a high quality sealant around the openings, create new paths by which moisture and other unwanted environmental effects may enter the internal structure.

Externally mounted piezoelectric patches are ideal due to having no effects on the internal mechanisms of a structure [3]. The impedance of a member can be measured between any two 
patches due to their dual nature of being both sensors and actuators. This dual sensing/actuating allows for monitoring of the structural condition of the cross-section of a member as well as the external surface and the internal areas at skewed angles between the sensors. Externally mounted patches can also easily be accessed and replaced if damaged, a feat impossible to embedded sensors. The distance at which externally mounted sensors must be placed is reliant upon the piezoelectric sensitivity constant of the material upon which they are attached.

\subsection{Damage Detection Methods}

Non Destructive Inspection (NDI) is a wide group of analysis techniques used in science and industry to evaluate the properties of a material, component or system without causing damage [10]. It is a highly valuable technique because it does not negatively or permanently alter the structure or component being inspected and can be used to inspect structures while they are inuse. Elastic wave analysis occurs when a signal is propagated through an elastic medium. The medium's particles will be displaced and a resultant force proportional to the displacement acts upon the particles to restore them to their original location. The main NDI techniques based on elastic waves are ultrasonics, accustom-ultrasonics and the mechanical impedance method.

Ultrasonics employs waves whose frequencies are above the upper threshold of human hearing (frequencies greater than $20 \mathrm{kHz}$ ) [9]. They rely on the reflection and scattering of elastic waves through a medium from field inconsistencies caused by local damage and flaws in the tested medium. Ultrasonic testing incorporates one or more of the following measurement parameters: 
frequency, impedance, time of wave transit, amplitude, angle of wave deflection, path length, and phase angle. Standard ultrasonic methods include the pulse-resonance, pulse-echo and pulsetransmission techniques [11]. More advanced ultrasonic techniques rely on the generation, propagation and detection of Love, Lamb, and Rayleigh waves [12]. Rayleigh waves are surface acoustic waves that travel on solids and whose direction of vibration and direction of propagation are the same (they do not have polarization). They are caused by localized impacts or by piezoelectric transduction. Lamb waves are Rayleigh waves that are guided in layers. Love waves are horizontally polarized shear waves guided by an elastic layer, their direction of propagation and direction of vibration are not the same. These guided waves are able to travel long distances with minimal amplitude loss and are therefore useful in SHM applications.

Acousto-ultrasonics is the combination of ultrasonic characterization along with acousticemission monitoring. It is a method that consists of monitoring and analyzing acoustic signals sent through a material. It is a highly sophisticated technique that uses digital signal processing and recognition algorithms. Acousto-ultrasonics considers the entire ultrasonic response, frequency as well as time, of a material and thus can be orders of magnitude superior to other ultrasonic techniques. Further advancement on acousto-ultrasonics was made by Duke [13].

The mechanical impedance method is a NDI technique that utilizes elastic wave analysis to measure the mechanical impedance of a structure or a structural member. The mechanical impedance method was pioneered by Lange [14] and Cawley [15]. Mechanical impedance is a measure of how much a structure or member resists motion when a given force is applied to it. It 
relates forces with velocities acting upon a mechanical system. Specialized equipment is used which can simultaneously measure the applied normal force and the induced velocity of a tested material structure or structural member. Impedance measurements are performed at regular intervals and a change in impedance is correlated with internal damage to the structure or disbonding to composite layers.

Both ultrasonic techniques have drawbacks that make them less appealing than NDI using the mechanical impedance method. The transducers needed to excite the ultrasonic signals are very bulky and can be obtrusive. In addition, their size requires that a fairly large normal (perpendicular) surface exist between the transducer and the test member. In contrast, the mechanical impedance method can be tested using piezoelectric-wafer active-sensors (PWAS). PWAS are small, non-intrusive, inexpensive, wide-band elastic wave generators/receptors, which can be intimately affixed to a structure and can actively interrogate it [16]. They can be placed in tight spaces and inside built-up structures. The PWAS can produce guided waves both through the cross-section of a member as well as parallel to the surface. Sensor arrays of PWAS can be installed to cover large surfaces due to their small size and low cost. It would be prohibitively obtrusive as well as expensive to install sensor arrays of conventional ultrasonic transducers. PWAS are usually manufactured from thin wafers of the piezoceramic lead zirconate titanate (PZT), chemical formula $\mathrm{Pb}(\mathrm{Zr}-\mathrm{Ti}) \mathrm{O} 3$. In differing from traditional ultrasonic transducers, PWAS are non-resonant devices with wide frequency-band capabilities. PWAS can be configured and wired into sensor arrays that are connected to various devices such as data concentrators and wireless communicators. 


\subsection{Report Organization}

This report contains the findings of an investigation to increase the piezoelectric effect and the reverse piezoelectric effect of cement paste for potential applications as a SHM material. The report is organized as follows:

Section 2 contains the specific procedure followed for experimental program and all background information relevant to each experiment. Section 3 examines the results obtained from the piezoelectric and reverse piezoelectric tests and discussed how these compare to current standards. Section 4 discusses all relevant conclusions obtained from the test results and further

considerations. The appendices include the data from the piezoelectric and reverse piezoelectric tests.

\section{Section 2: Experimental Methods}


The specific procedures and methods followed for each experiment is discussed in the following sections.

\subsection{Specimen Preparation}

To make specimens for the study, rectangular molds with inner-dimensions of $5.72 \mathrm{~cm} \mathrm{X}$ $11.43 \mathrm{~cm} \mathrm{X} 11.43 \mathrm{~cm}$ were made from cut pieces of Boltaron type-I PVC and adhered together using IPS WELD*ON \#16 solvent cement. The inside of each mold was covered with DOW CORNING high vacuum grease to insure minimal water leakage and ease of specimen removal. Control molds were constructed using solid end pieces while test molds were constructed using end pieces with a repeating hexagonal drill pattern in them. Hexagons had a diameter of $1.27 \mathrm{~cm}$ and holes were drilled using a \#40 drill bit and created using a computerized drilling machine (FFigure 1: Hexagonal Pattern). The hexagon size was determined by the minimum clearance needed to wire the boxes by hand and the drill bit size was constrained by the smallest drill bit that could be used to drill the PVC without breaking. Consolidated Electronic Wire \& Cable 801/0 22AWG hook up wire was hand placed through opposite holes in the test molds and soldered in columns. Some specimens had bolts placed half-way through them to induce damage for detection during the reverse piezoelectric effect testing phase.

$5.08 \mathrm{~cm}$ X $5.08 \mathrm{~cm}$ X $5.08 \mathrm{~cm}$ molds were also made to check the change in resistance of cement paste as it cures to determine what voltage should be used for the direct piezoelectric tests. The 
molds were constructed using the same method as the larger molds but with only one hexagon wired up, the rest of the holes in the ends were filled with vacuum grease.

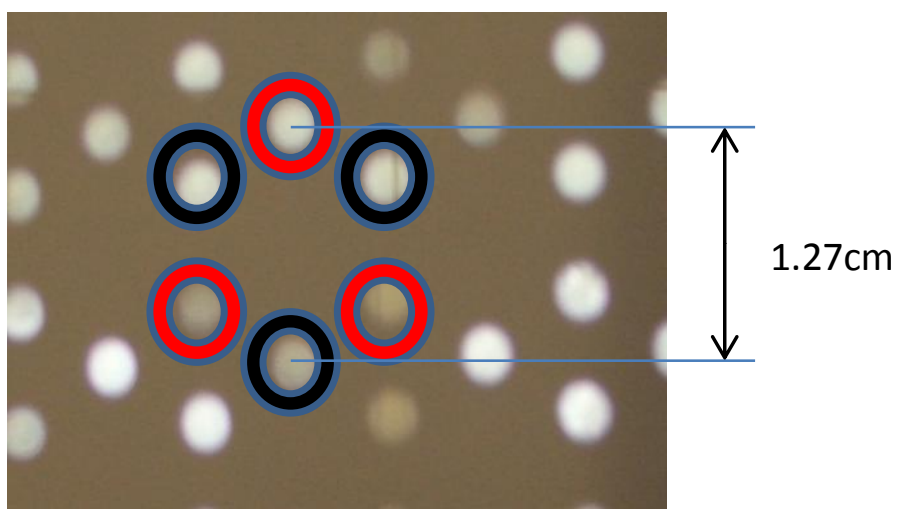

Figure 1: Hexagonal Pattern

Cement paste was mixed in accordance with ASTM standard C305. A 0.45 water to cementations material ratio was used because it is a w/c ratio commonly used for structural cement. For each mixture made, a pair of samples was produced, one test sample cured under an electric current and one control sample cured normally. The cement paste was placed into the molds and a table vibrator was used to compact the paste and eliminate entrapped air.

The wired sample was subjected to a $1 \mathrm{~V}$ electrical current in voltage control during the first 24 hours of curing. A series circuit was made between a Kepco BOP 20-20M analog power supply, 
a $1 \Omega$ resistor, an Agilent Technologies U3606A digital multimeter and the test specimen (Figures 3 and 4). Current readings were gathered from the wired sample in 15 second increments during the initial 24 hours using the digital multimeter and a MATLAB program. The specimens were demolded after one day and allowed to cure at room temperature for 28 days.

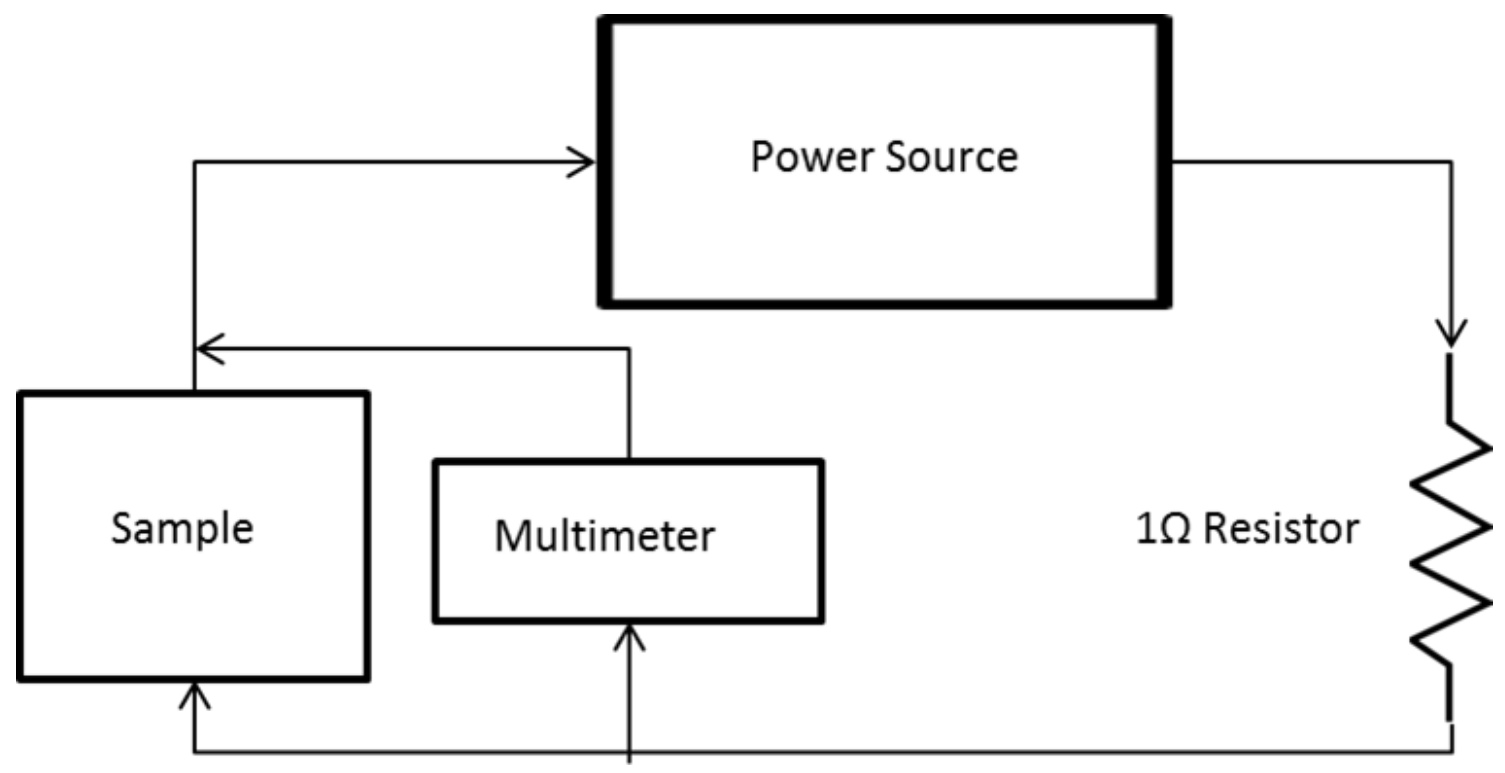

Figure 2: Experimental set up diagram

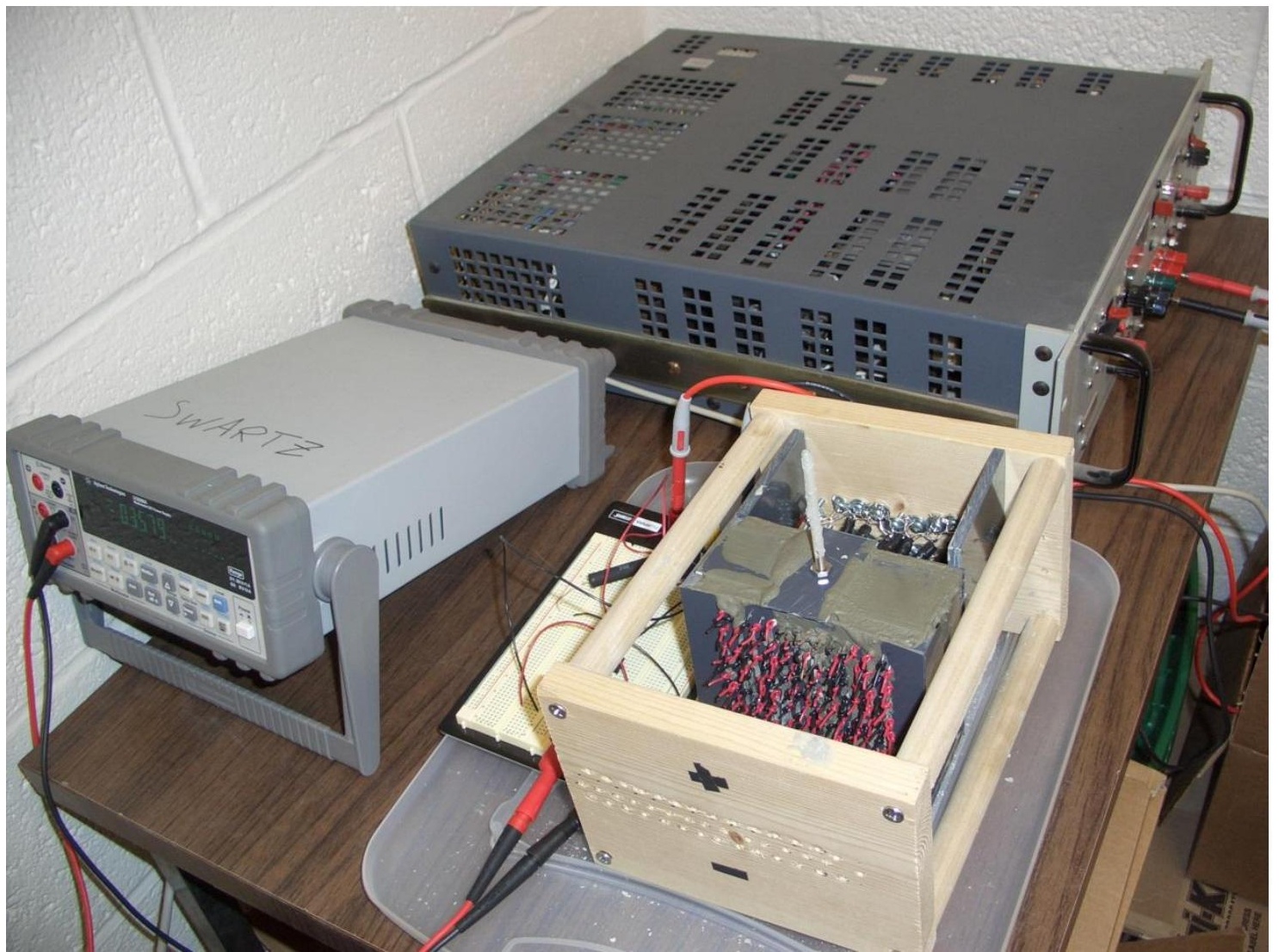


Figure 3: Experimental set up

\subsection{Resistance Testing}

During the curing of the Batch1 test specimen it was noted that at the chosen voltage of 4 volts, bubbles were seen to form at the top of the specimen. These bubbles persisted even when the current was reduced to 2 volts. When the specimen was observed the next morning it was observed that the multimeter used to cure the cement paste under a current had tripped due to exceeding its maximum current of 3 amps; this lead to a series of tests created to verify the maximum current that could be applied to the specimens.

The small molds for resistance testing were prepared individually using the same method as described above. One sample had no current running through it and had its initial 24 hour resistance measured in one second increments (Figure 4). The other samples had currents of 1V and $4 \mathrm{~V}$ run through them during the initial curing period. These samples had their currents measured every second for 24 hours and the resistance calculated using Ohm's law ( V = I* R ). 


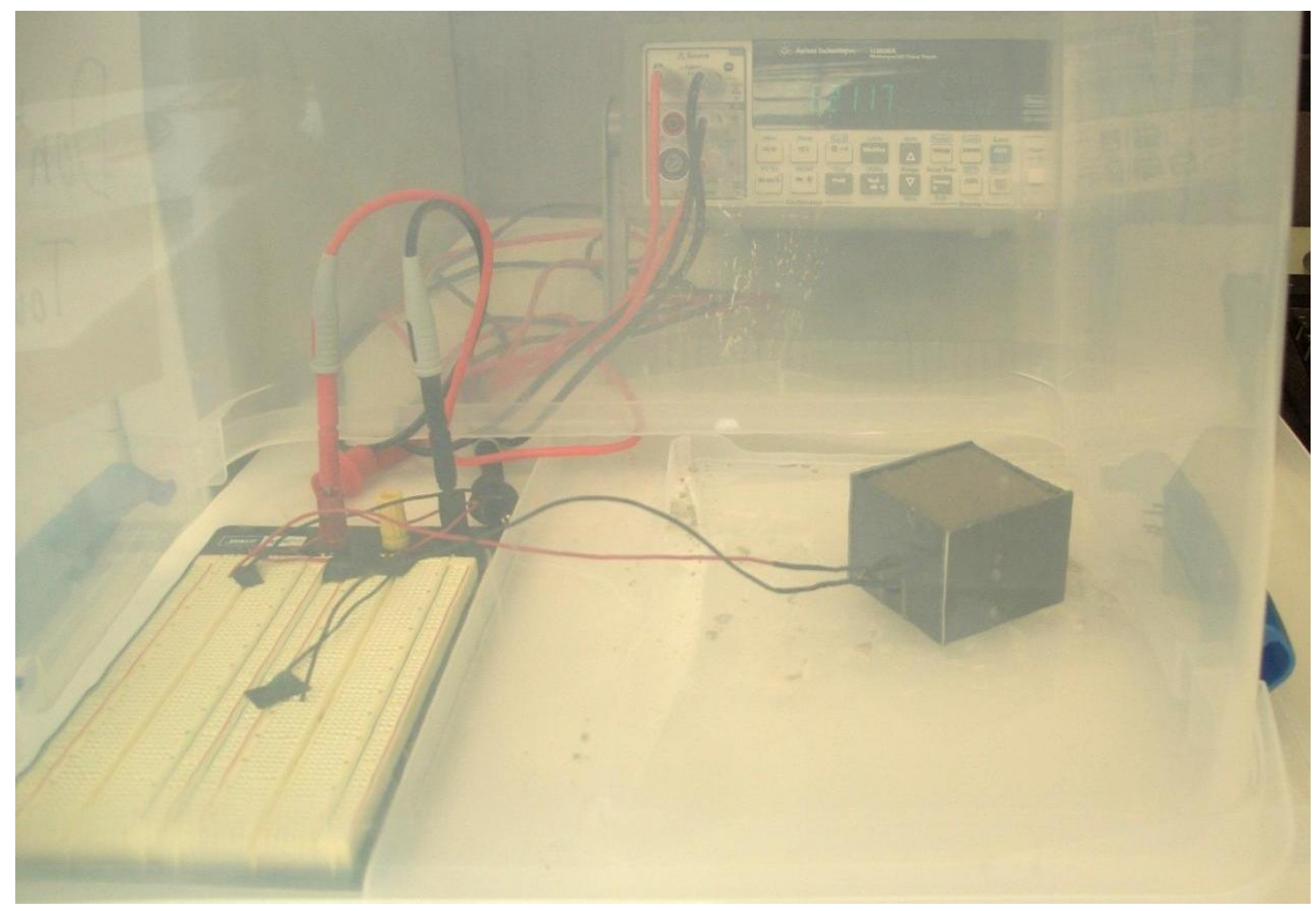

Figure 4: Resistance Cube

It had been initially hypothesized that curing cement paste under a current would increase its resistance due to the supposed creation of dipoles within the paste. It turns out that based on a

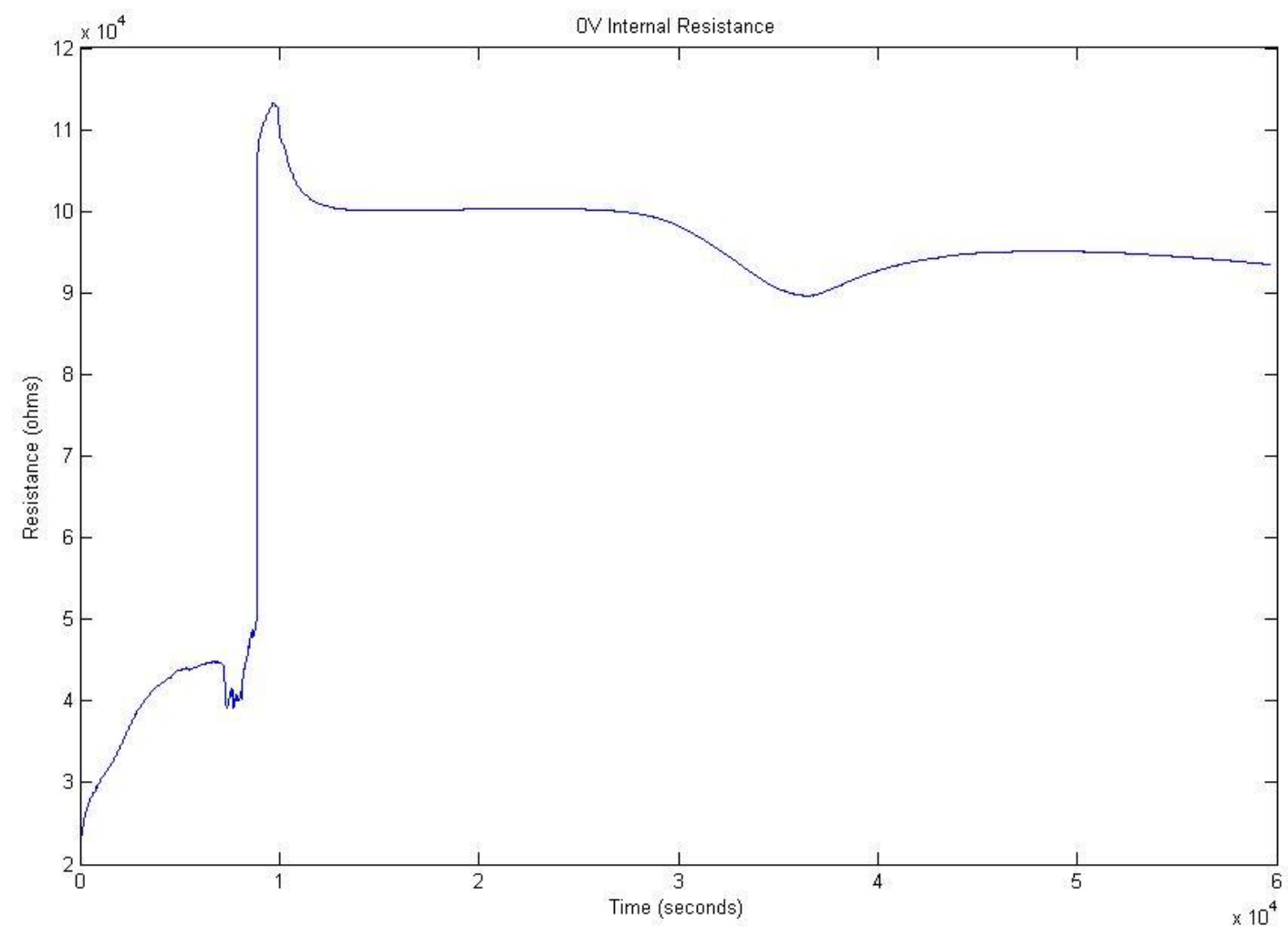


comparison between the resistance control small cube and the $1 \mathrm{~V}$ and $4 \mathrm{~V}$ test specimens (Figures 5, 6 and 7), running current through the paste actually decreased the long-term resistance significantly. It had also been seen during exploratory testing that curing the paste under a current greater than $1 \mathrm{~V}$ caused bubbles to form within the paste. Based on the formation of bubbles and the results of the change in resistance caused by initial curing under a current, it was decided that the test specimens would be cured under a $1 \mathrm{~V}$ current.
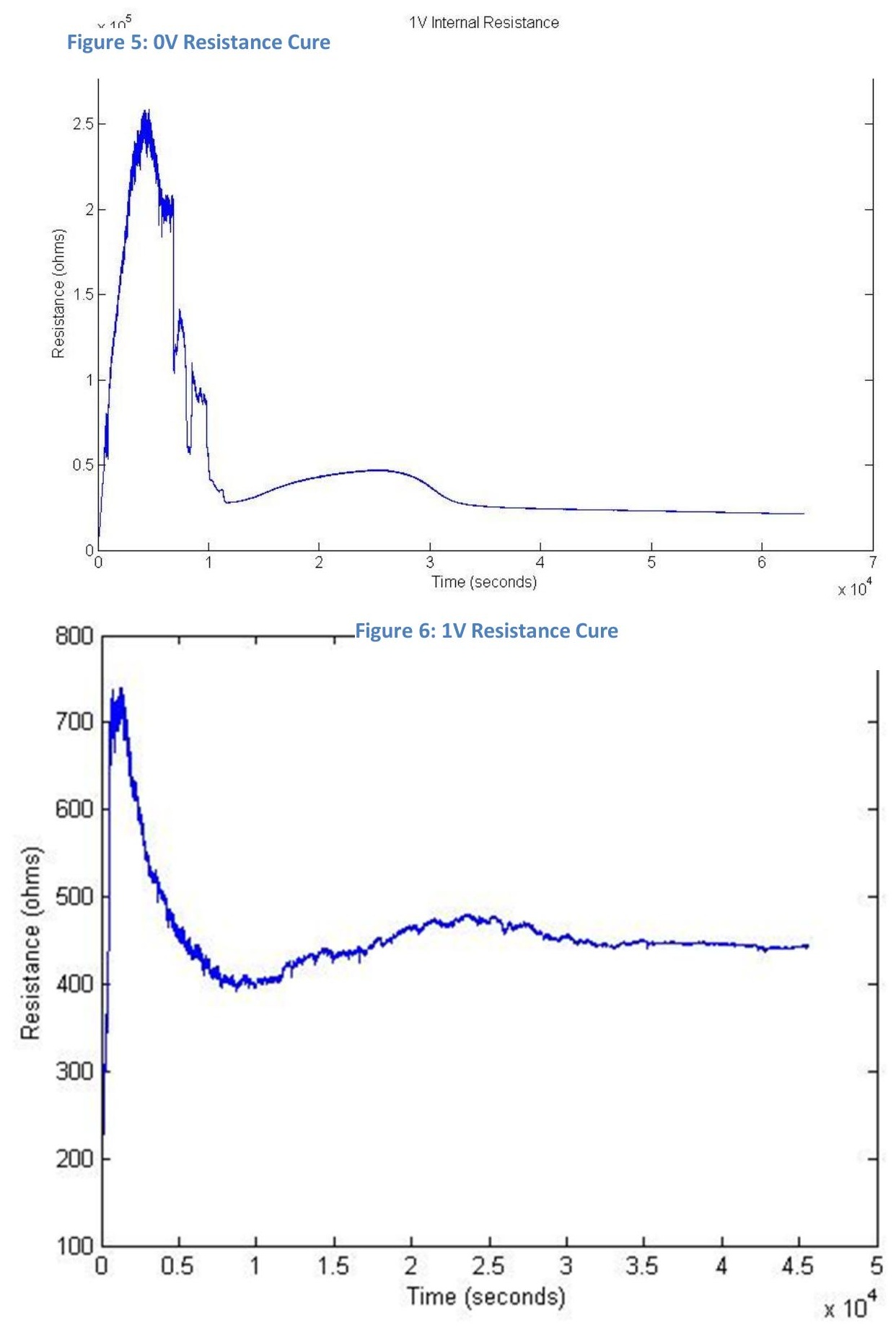
After 28 days had passed, the specimens were prepared for testing. Samples were cleaned and had two strips of $1.27 \mathrm{~cm}$ width 3M EMI Aluminum Foil Shielding Tape 1181 applied to both the top and bottom smooth surfaces. Pelco Colloidal Silver Paste was then applied to the edges of each piece of aluminum tape to increase conductivity and ensure full adhesion between the tape and the cement paste samples. Coaxial cable was connected to the samples via the aluminum tape to allow for as clear signal transfer as possible. A second batch was prepared, but both of its specimens cracked before the maximum load was applied to them, resulting in the need to void the data collected from them. It is believed that the cement paste used to prepare this batch had been compromised by moisture in the lab. Batch3 did not have any of these issues.

\subsection{Direct Piezoeolecetric Effect Test}


The piezoelectric effect is observed when a dynamic load is applied to a material. To mimic this, the samples were cyclically loaded using a MTS compression machine (Figure 8). Samples were placed into the machine with PVC plates between them and the machine to prevent the transfer of stray current from the machine to the samples (Figure 9). A Campbell Scientific CR9000X data acquisition system was used to collect the voltage data at a sampling rate of $50 \mathrm{~Hz}$. Samples had a pre-load of $226.8 \mathrm{~kg}$ placed on them for 3 minutes before the cyclic loading began.

The samples then had a varying cyclic load applied to them for 60 cycles at a cycle time of 2 seconds, data was then collected for an additional 5 minutes to catch any possible residual effects from the loading. The regimen consisted of increasing maximum loads of $2268 \mathrm{~kg}, 3629 \mathrm{~kg}$, $4536 \mathrm{~kg}, 4990 \mathrm{~kg}, 5443 \mathrm{~kg}, 15897 \mathrm{~kg}, 6350 \mathrm{~kg}$ and $6804 \mathrm{~kg}$. Each sample was tested twice to see if there was any dispersal of energy during the initial testing sequence. 


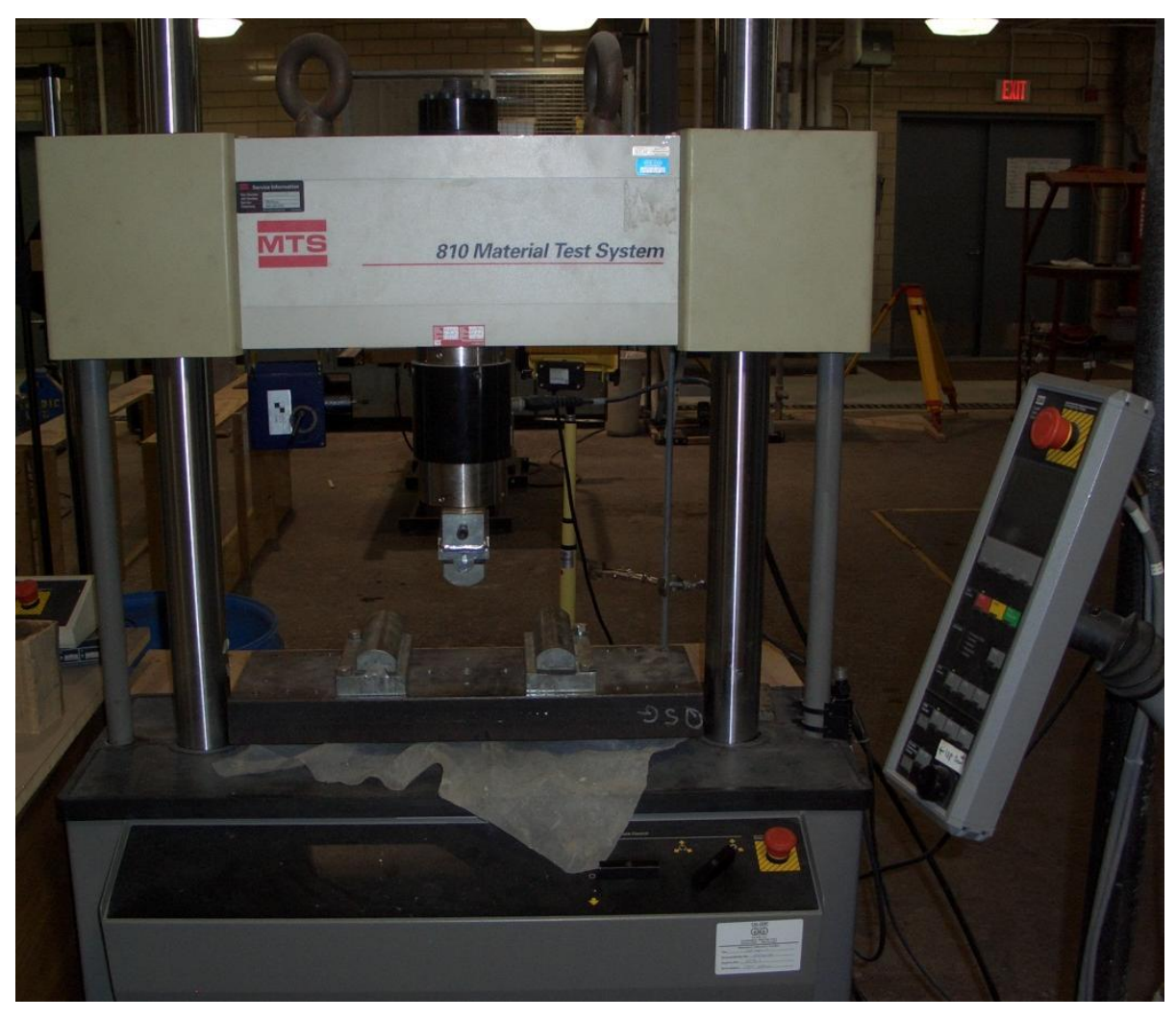

Figure 8: MTS Compression Machine 


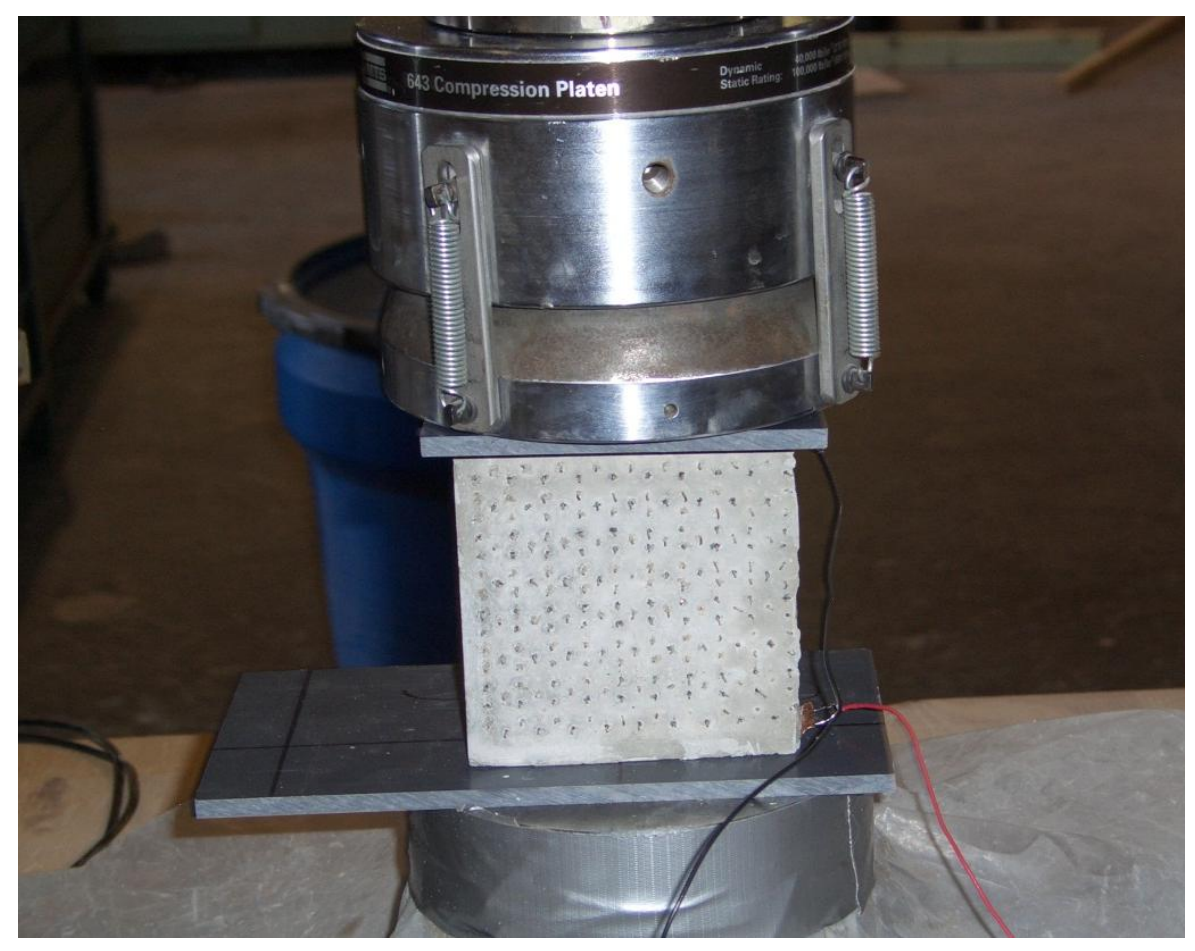

Figure 9: Specimen in MTS machine

\subsection{Indirect Piezoelectric Effect Testing}

The indirect piezoelectric effect is observed when an electric signal is sent through a material, resulting in an applied stress. To test this, a set-up was constructed using the samples, an Agilent Technologies MSO7014A waveform generator, lead zircotitanate (PZT) piezoectric patches and an Agilent Technologies oscilloscope (Figure 10). The samples were connected to the waveform generator via coaxial cable. Each of the four free sides of the sample (the four sides that did not have aluminum tape adhered to them) had a single PZT patch affixed to the middle of them using wax oriented to measure stress perpendicular to the face of the specimen. 
The \#1 and \#3 PZT patches were affixed to the top and bottom of the samples (the sides that had the aluminum tape affixed to them and in the direction of the dynamic loading), the \#2 and \#4 PZT patches were affixed to the wide sides of the sample. The patches were connected to the oscilloscope with each one getting their own channel and used solely for their sensing capabilities. An AC signal was sent through each sample and the result sensed by the PZT patch was recorded by the oscilloscope. A sinusoidal AC waveform having a peak to peak voltage of $10 \mathrm{~V}$ (the maximum voltage able to be output by the waveform generator) was sent through each specimen. The frequency was varied with each test. Frequencies used varied from between $10 \mathrm{~Hz}$ and $327.680 \mathrm{kHz}$. It has been shown that a range of $30-400 \mathrm{kHz}$ can be effective for measuring structural damage [9]. Frequencies higher than $200 \mathrm{kHz}$ are favorable in localized sensing while frequencies below $70 \mathrm{kHz}$ are best for covering a larger sensing area. Results for each pair of test and control specimens was compared to see if being cured under an electric current had any effect on the indirect piezoelectric effect of cement paste. The Batch3 samples then had their embedded bolts struck with a hammer to create internal damage and were re-tested to see if the piezoelectric signals changed in the test specimen as compared to the control specimen. 


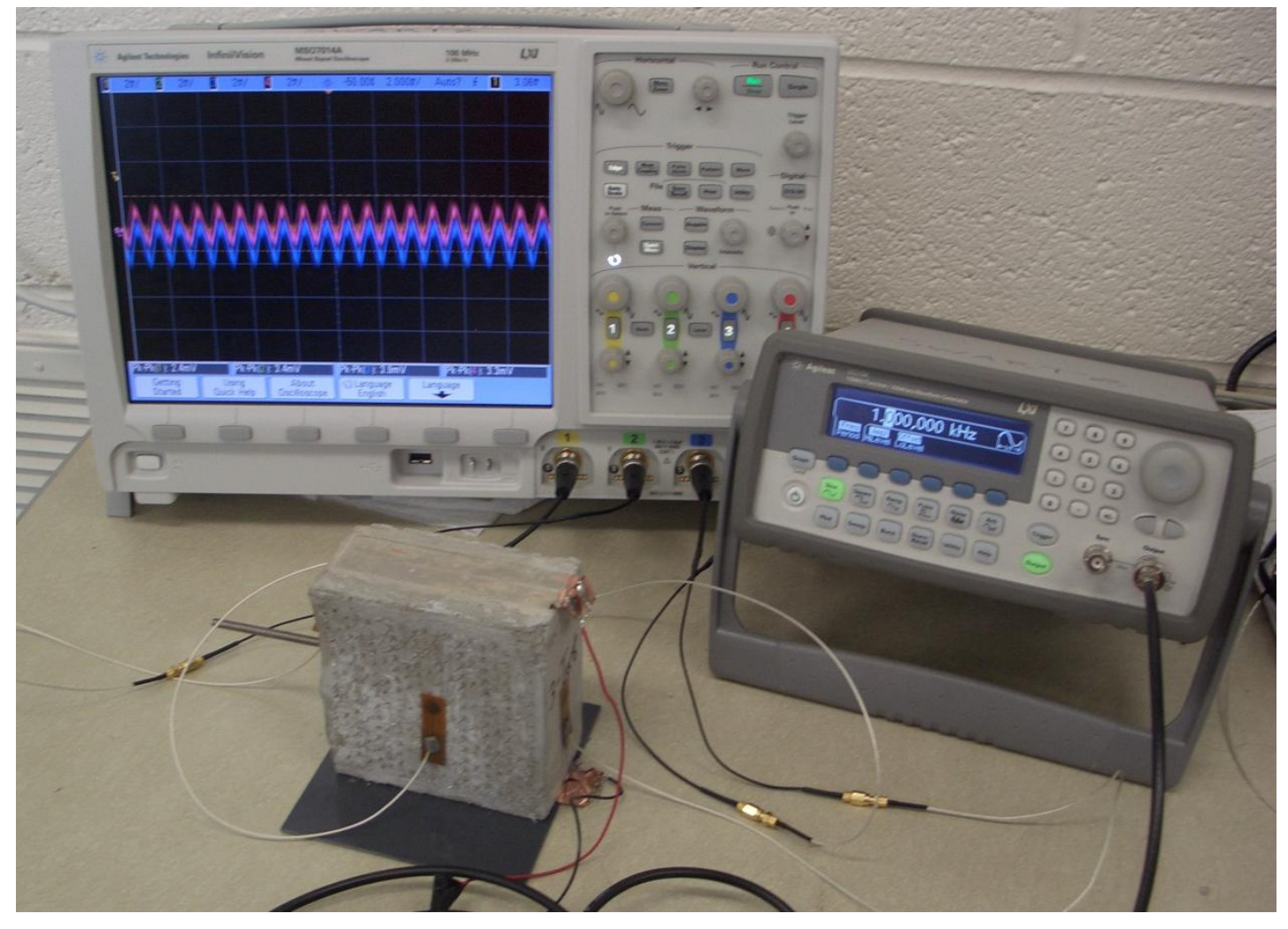

Figure 10: Indirect Test Setup 


\section{Section 3: Results}

\subsection{Direct Piezoelectric Testing}

The collected data from the compression tests was used to calculate the piezoelectric voltage constant $\left(\mathrm{g}_{33}\right)$. Figures 11-14 show the outputted voltage vs. applied load for a few of the tests. Figures 15-18 show the calculated $\mathrm{g}_{33}$ constant versus the applied load for control and test specimens of hardened cement paste during both the initial repeated compressive loading regimen and the 24-hour repeatability regimen. The control specimens had a voltage constant that was strain-dependent, as seen in the figures. The calculated variance can be seen in Table 1. Controll's constant had a decreasing trend during the initial testing and a varying trend during the final testing, with an increasing variance as the applied load was increased. Test1's constant had no discernible pattern during either testing period and apart from the initial $2268 \mathrm{~kg}$ force, had very little change in voltage constant and a very small variance. Control3's initial and final constant's both had decreasing patterns and relatively little variance. Test3 had less variance than Control3, although its final testing had an increasing pattern. 
The goal of the experiments was to increase the voltage constant in the test specimens but as shown in the figures, the constant was not actually increased but rather it was standardized. The standardization is useful because it allows for more accurate damage detection readings and is due to the fact that repeatability is a critical factor for SHM applications. As shown in the table, the control specimens had a voltage constant that had a greater variance that depended on the applied load.

Table 1: Variance in Voltage Constant

\begin{tabular}{|r|r|}
\hline & variance \\
\cline { 2 - 2 } Control1 Initial & $1.98 \mathrm{E}-07$ \\
\hline Test1 initial & $1.20 \mathrm{E}-07$ \\
Control1 +24hr & $1.86 \mathrm{E}-07$ \\
\hline Test1 +24hr & $3.61 \mathrm{E}-09$ \\
\hline Control3 Initial & $2.34 \mathrm{E}-05$ \\
\hline Test3 Initial & $2.05 \mathrm{E}-07$ \\
Control3 $+24 \mathrm{hr}$ & $1.89 \mathrm{E}-05$ \\
\hline Test3 $+24 \mathrm{hr}$ & $2.57 \mathrm{E}-06$ \\
\hline
\end{tabular}



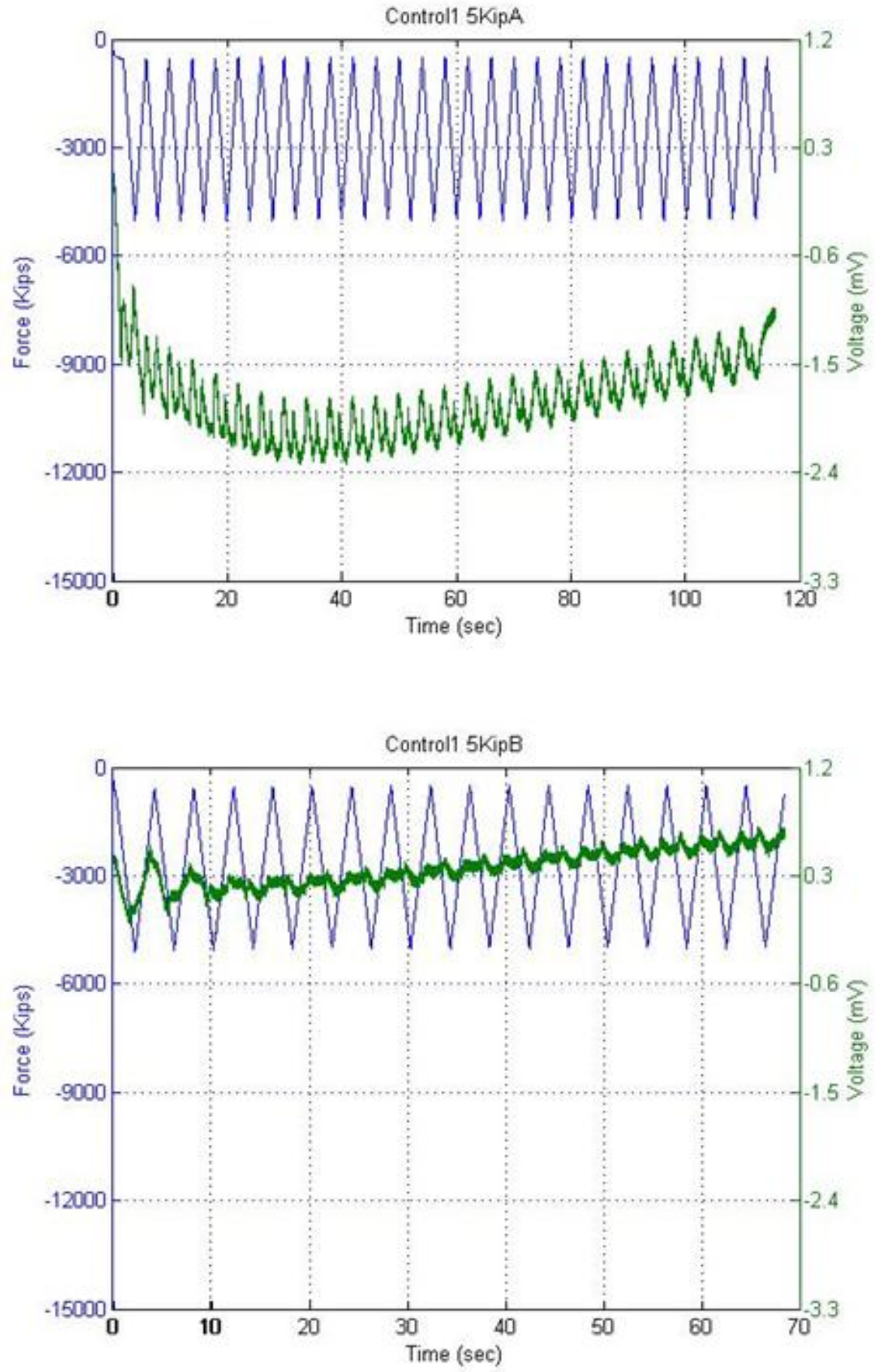

Figure 11: Control1 5Kip Test Regimen 

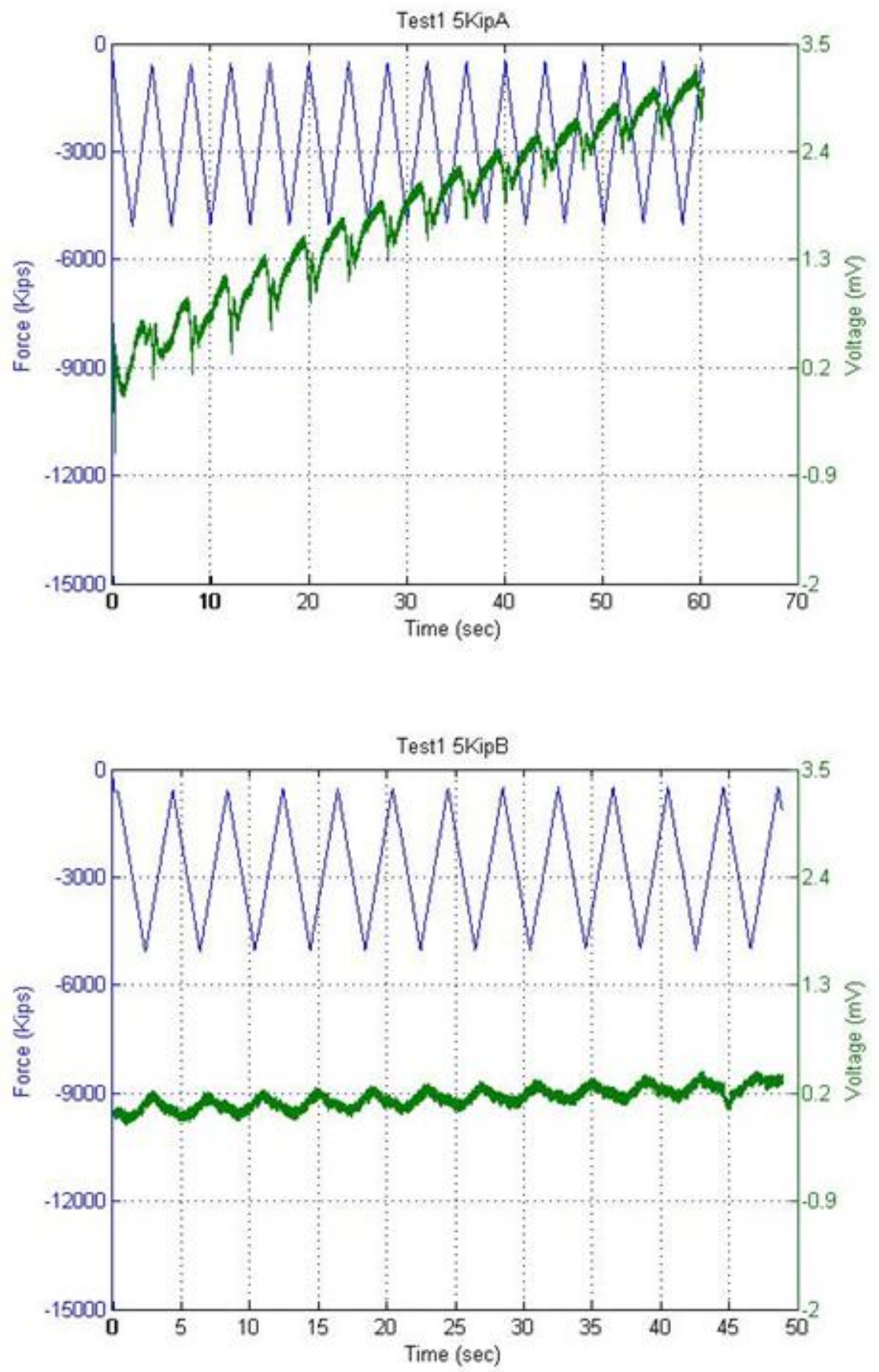

Figure 12: Test1 5Kip Test Regimen 

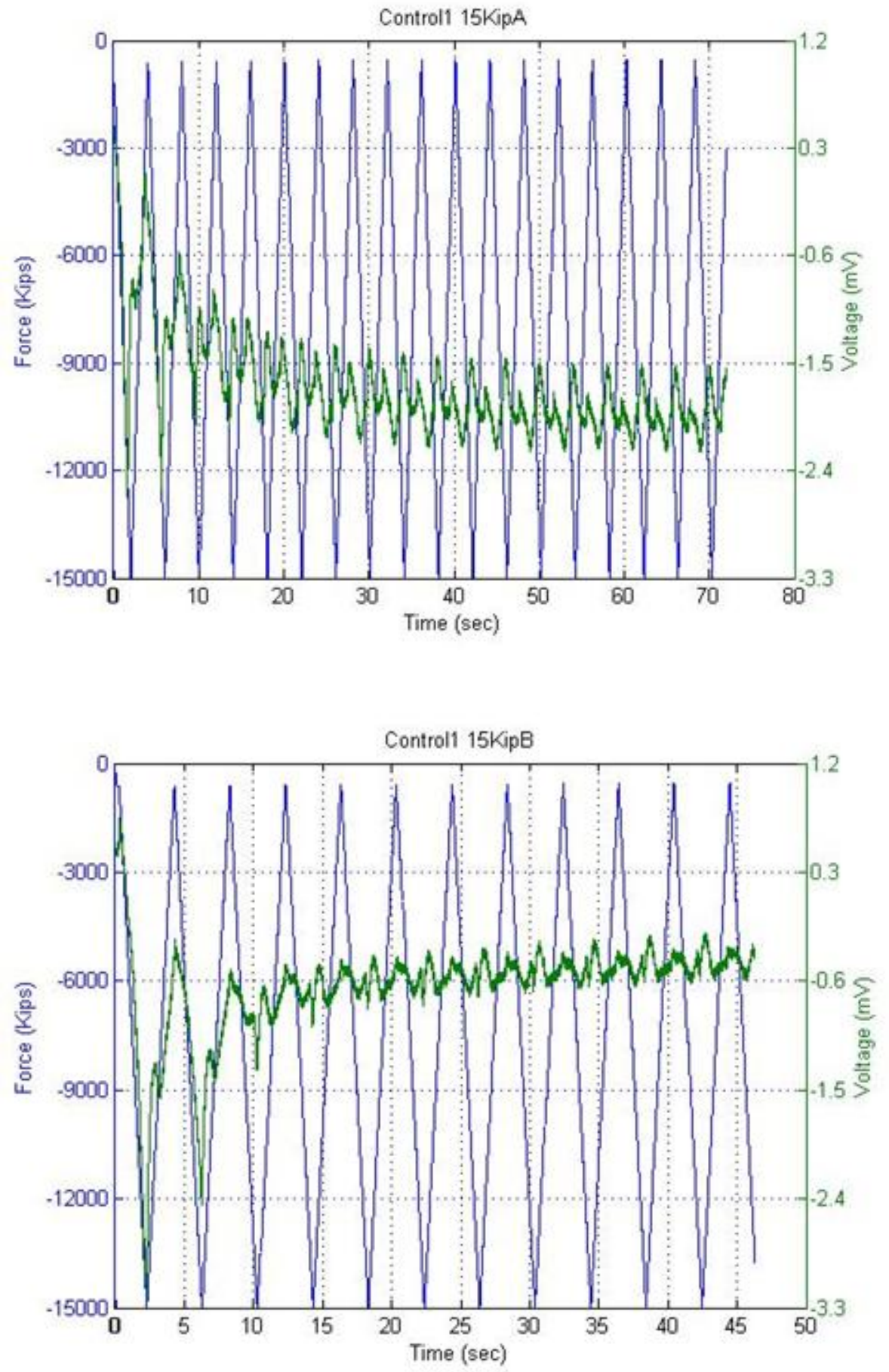

Figure 13: Control1 15Kip Test Regimen 

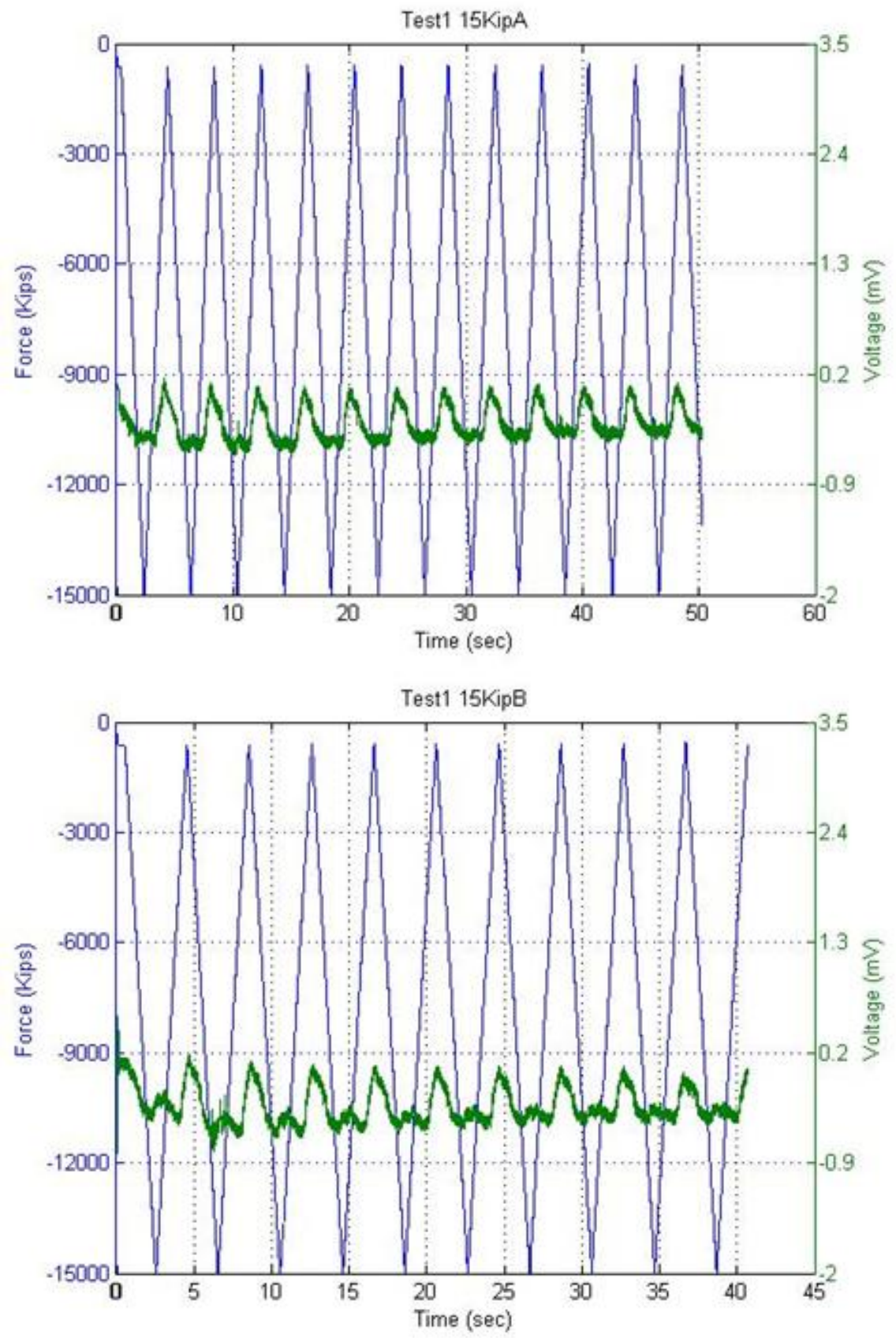

Figure 14: Test1 15Kip Test Regimen 

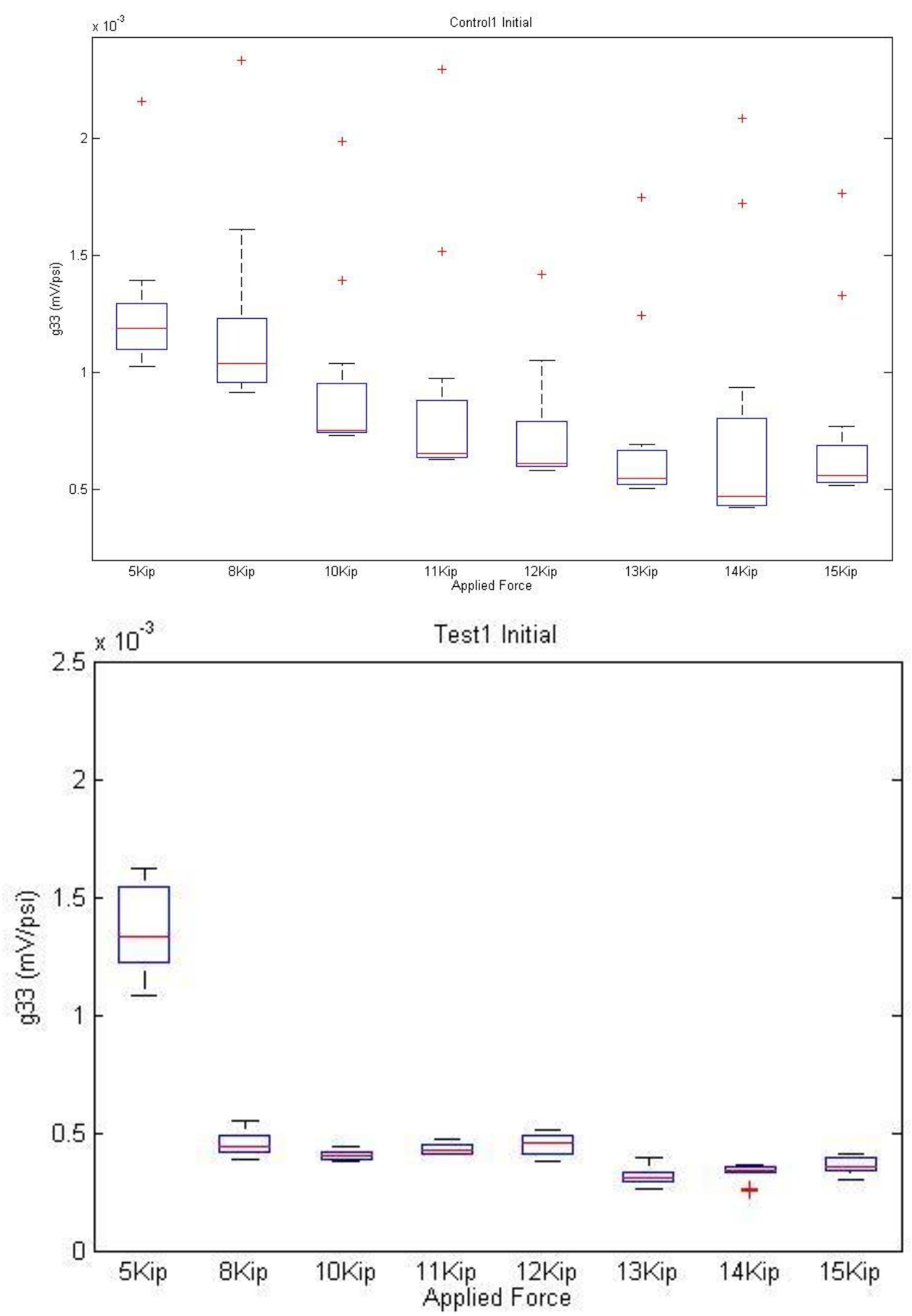

Figure 15: Batch1 Initial Voltage Constants 

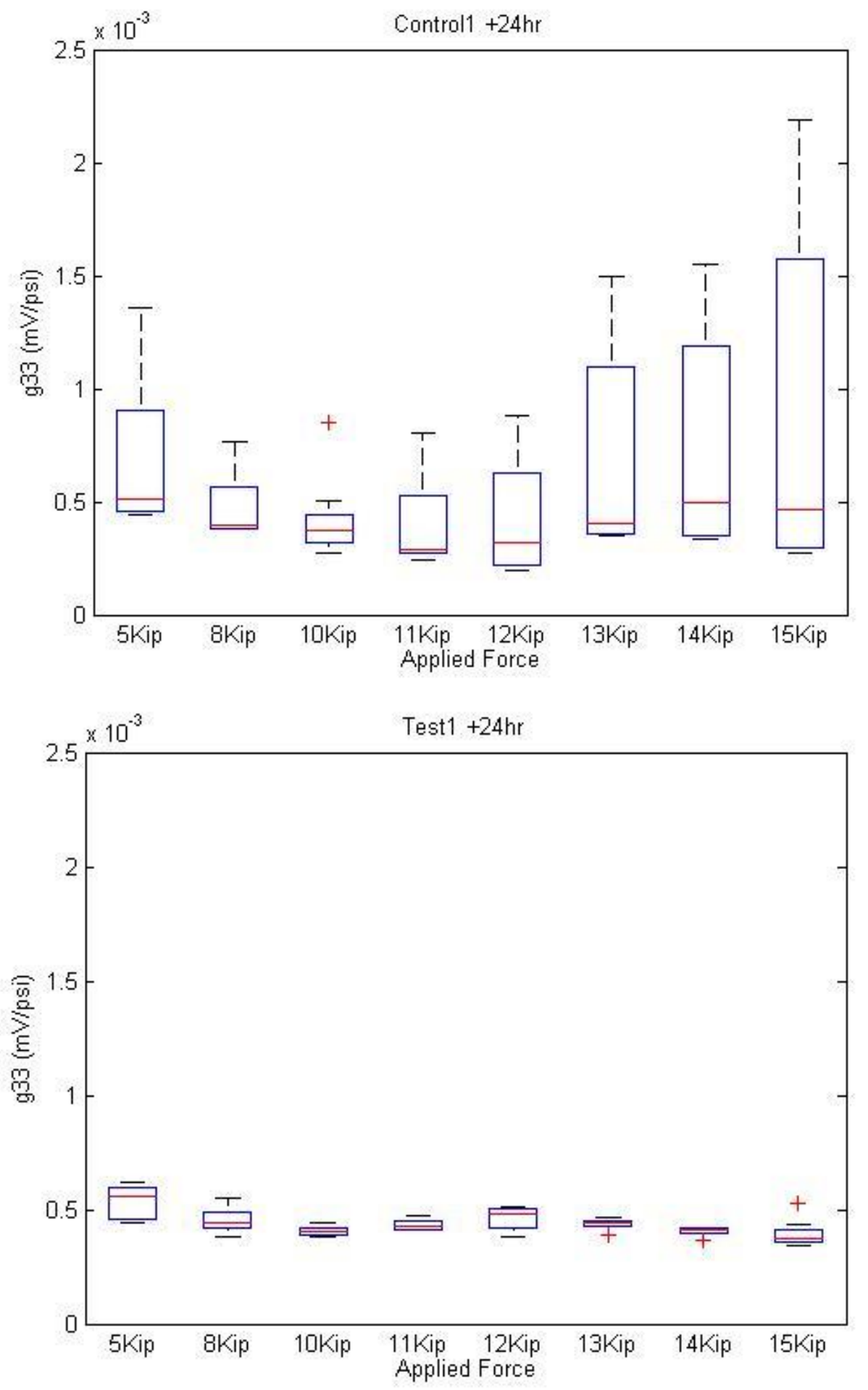

Figure 16: Batch1 24 Hour Voltage Constant 

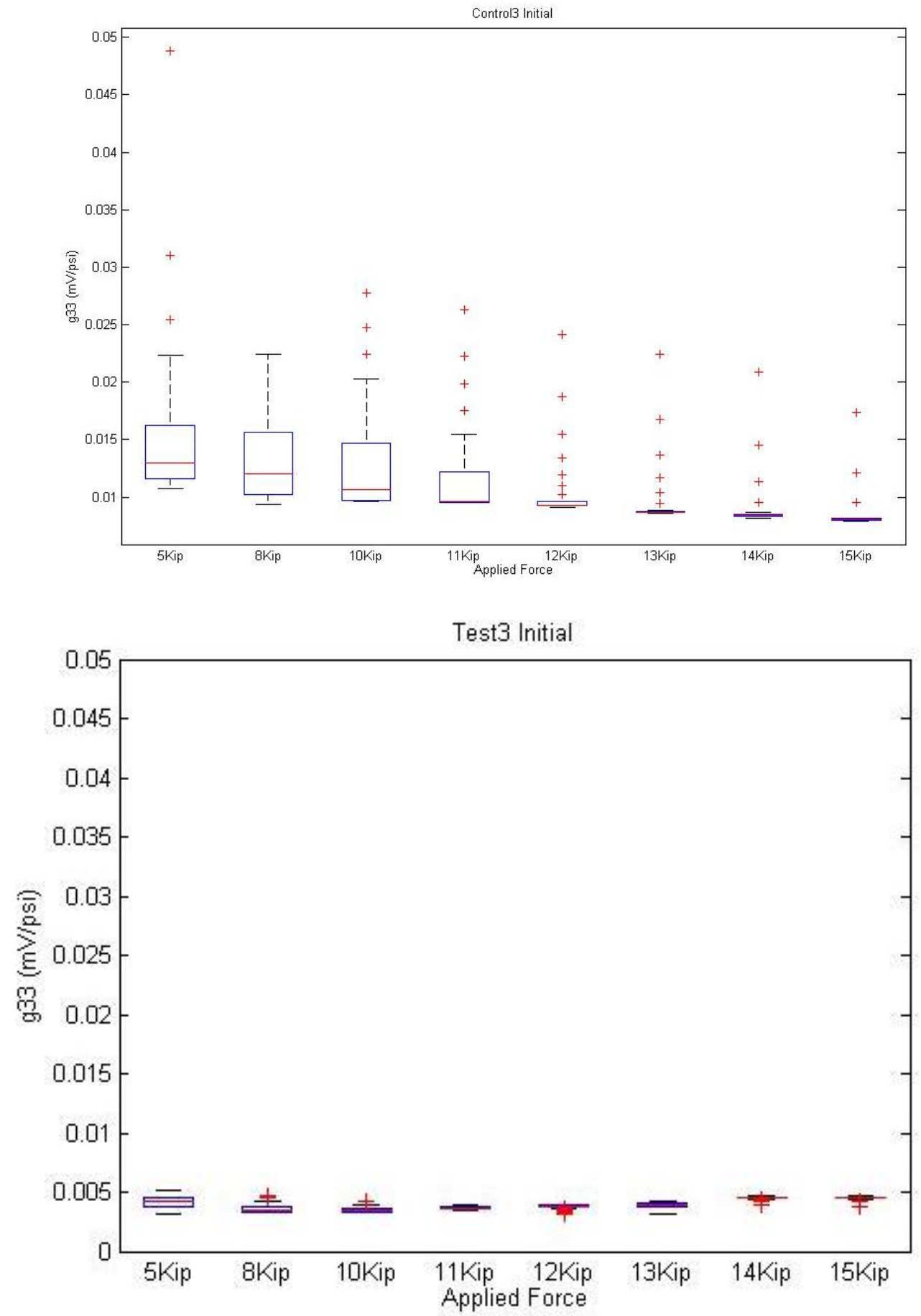

Figure 17: Batch3 Initial Voltage Constant 

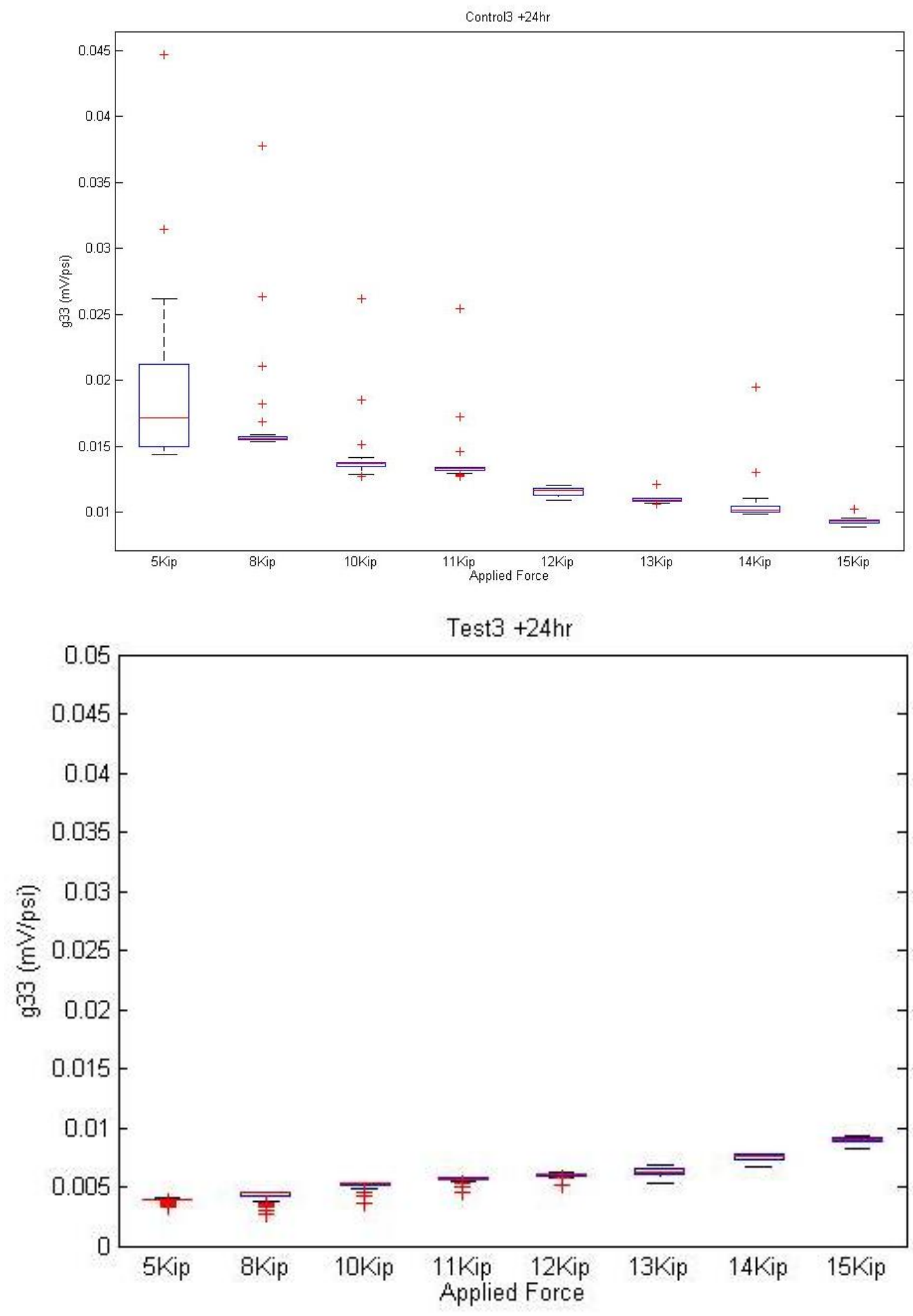

Figure 18: Batch 324 Hour Voltage Constant 


\subsection{Indirect Piezoelectric Testing}

The voltage measured by the PZTs attached to each specimen was multiplied by the piezoelectric coefficient $\left(\mathrm{d}_{31}\right)$ of the PZT provided by the manufacturer to calculate the strain produced by a sinusoidal wave of various frequencies and a $\mathrm{Vpp}$ of $10 \mathrm{~V}$. The resulting strains were then plotted against frequency on a semi-log scale (Figures 19-21). Both of the specimens of Batch1 appear to reach a resonance frequency at $320 \mathrm{~Hz}$ as noted in the figures. The strain increases until it reaches a maximum at $320 \mathrm{~Hz}$ then decreases to the maximum tested frequency. The control sample had a marginally larger maximum strain than the test sample. Both of the specimens of Batch3 had increasing strains along the length of their plots and both had similar strains for corresponding frequencies. The Control3 measurement at $5120 \mathrm{~Hz}$ appears to be erroneous due to the spike in strain at that frequency and also because there is no such spike at that frequency when the sample was damaged and re-measured.

The Batch3 control showed an overall decrease in average strain when damaged while the test specimen had an overall increase in average measured strain when damaged. They both showed a similar increasing trend in their strains as when they were undamaged. The Control3 specimen had an overall decrease in average strain of $7.8 \%$ while the Test 3 specimen had an overall increase in average strain of $2.9 \%$. 

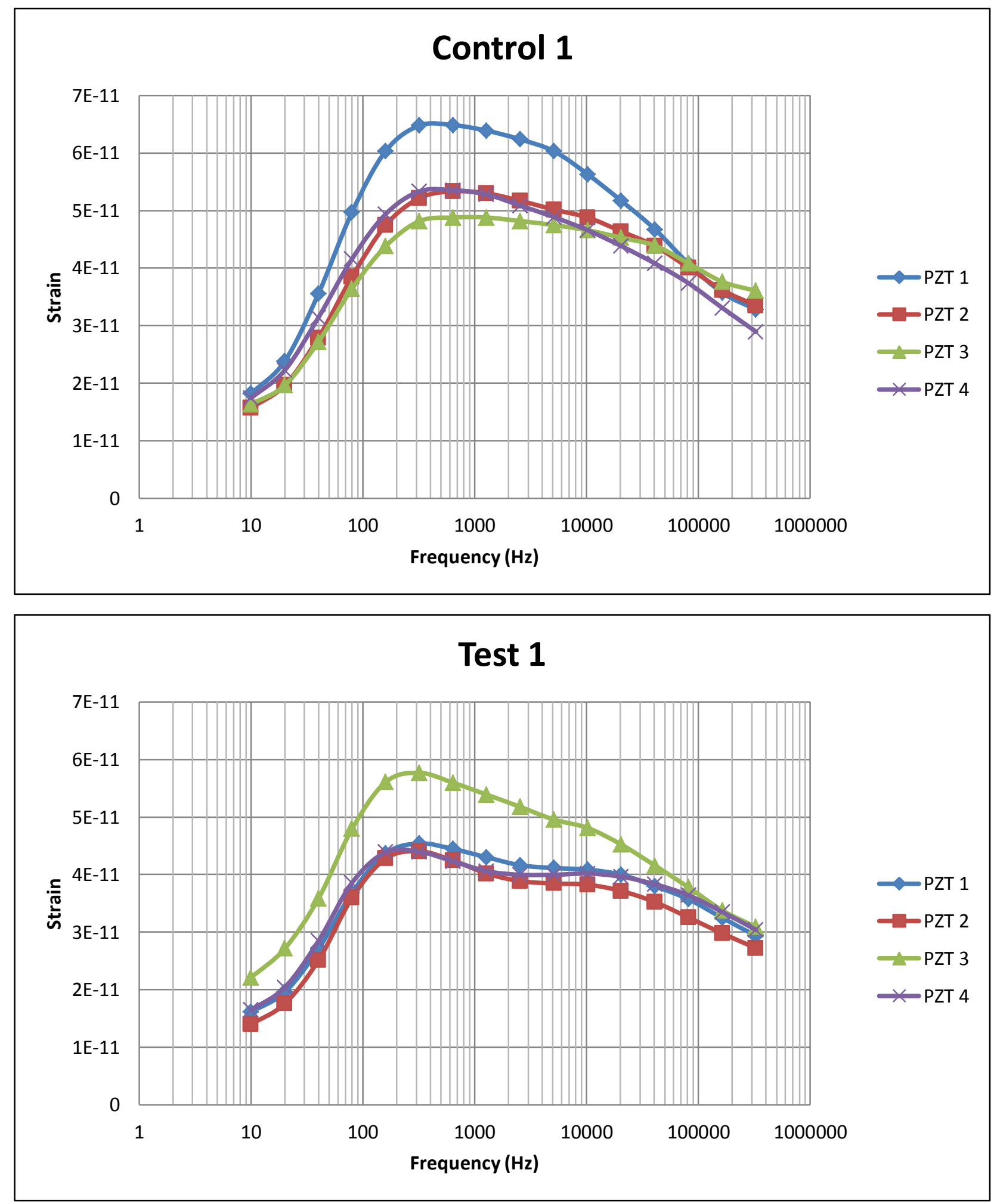

Figure 19: Batch1 Indirect Piezoelectric Testing 

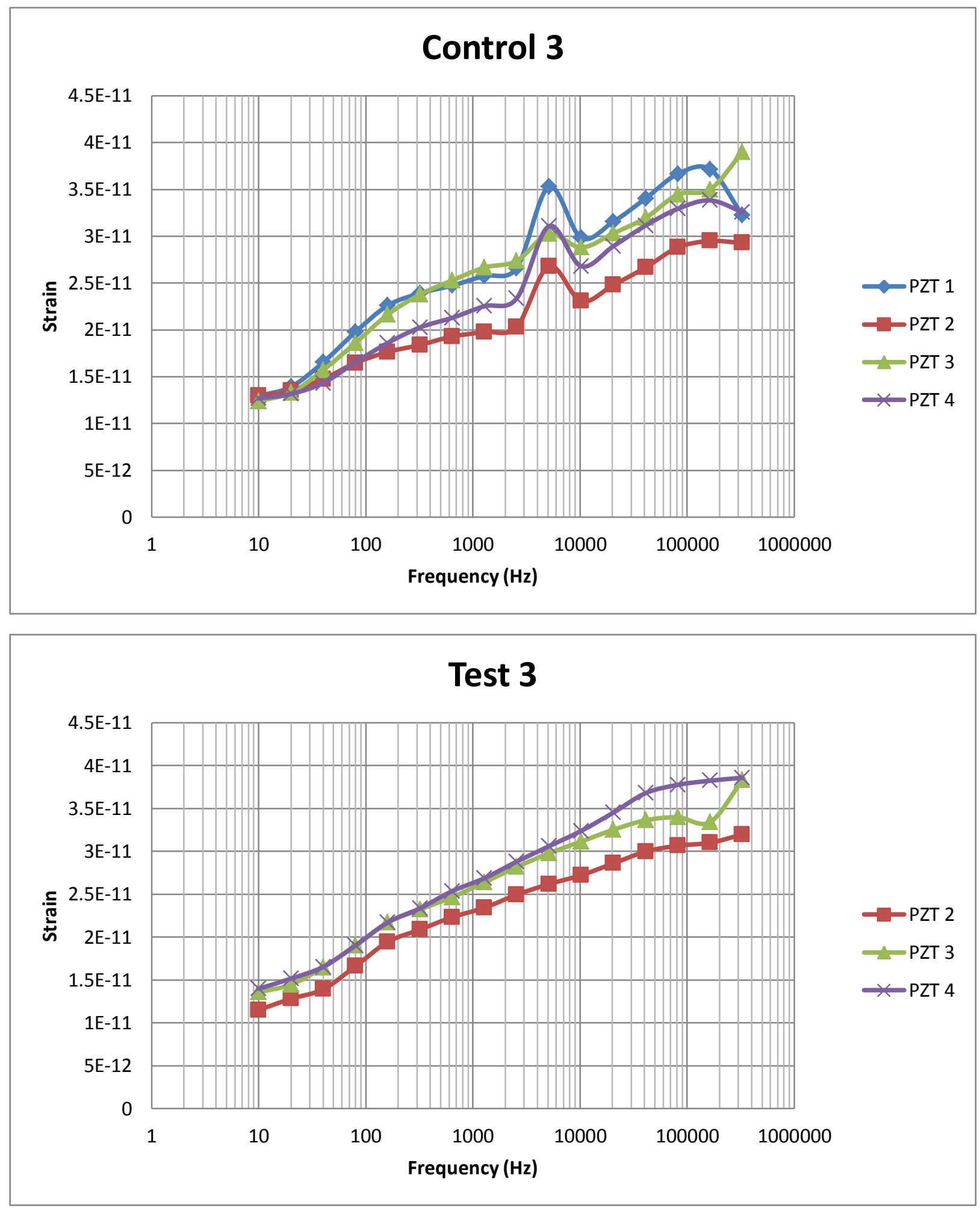

Figure 20: Batch3 Indirect Piezoelectric Testing 

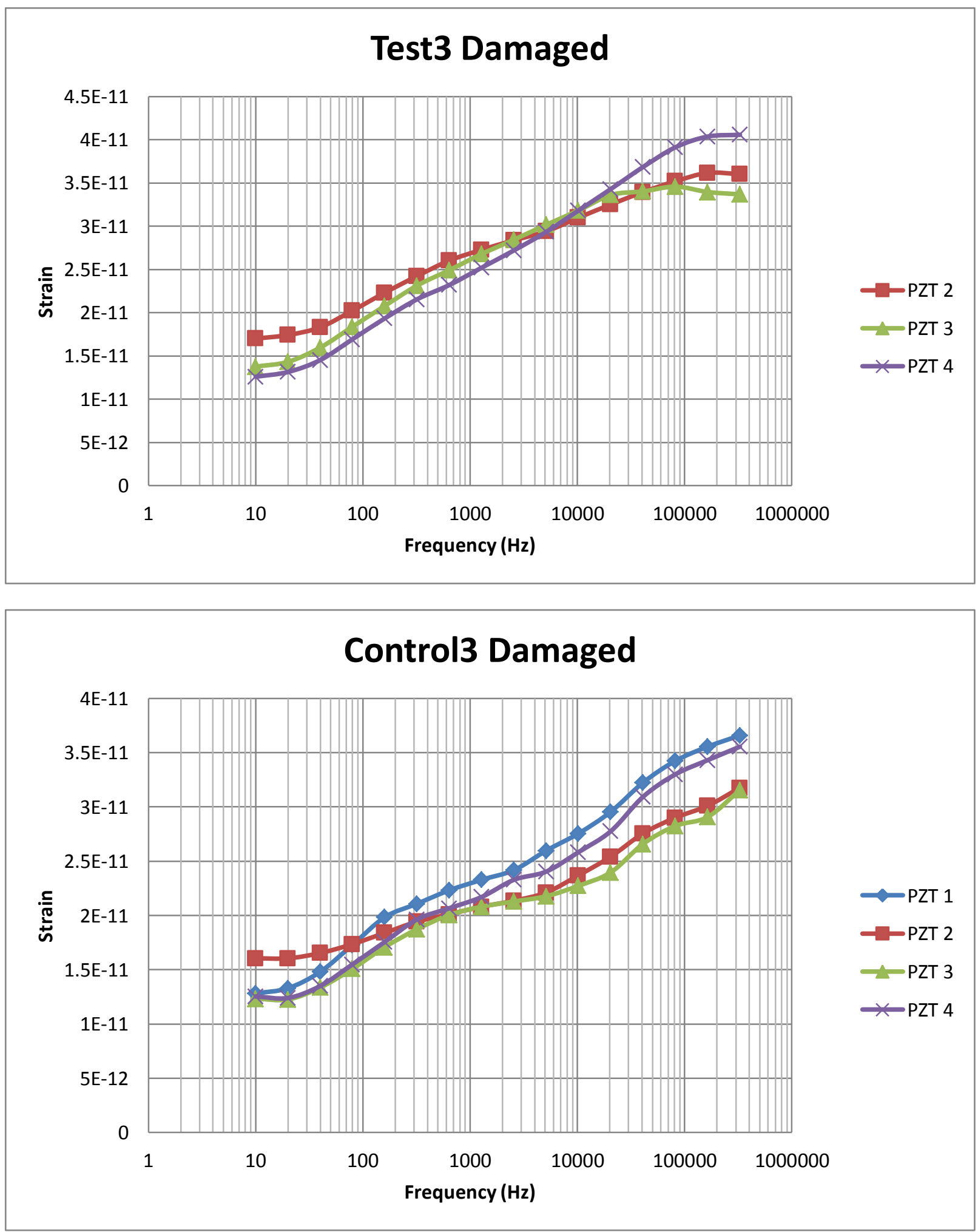

Figure 21: Batch3 Indirect Piezoelectric Testing After Damage 


\section{Section 4: Conclusions and Future Work}

\subsection{Conclusions}

The standardization of the piezoelectric voltage constant in the test samples is due to the fact that they were cured under current. The force dependence of the voltage constant in standard cement paste means that under loads, damage is unable to be determined unless the applied load is known. In addition to this the voltage-cured cement paste has a constant piezoelectric voltage constant even after loads are repeatedly applied, allowing for the simplification of damage calculations upon a structural member.

The increase of the strain/voltage ratio in the test samples means that a lower voltage threshold can be used for damage detection, reducing the energy needed to power the PZT patches and increasing the sensitivity to internal damage and debonding. The presence of a resonance frequency in the first batch may be due to the fact that the samples were allowed to cure for a year before testing as opposed to the third batch, which was only allowed to cure for four months before its indirect piezoelectric properties were tested. The differences between the 2 control samples and the test samples could be due to mixing inconsistencies or the 8 month difference in the testing times for the two batches. 


\subsection{Future Work}

Results obtained in this study indicate that further work in this area is warranted. First and foremost, the grid pattern and wires used to cure samples under an electric current will need to be machined to be much smaller and more compact to increase the effect of the current and, perhaps, better mimic natural piezoelectric crystal structures. Different water/cementatious materials ratios should be tested to see if the piezoelectric effect is affected by the amount of water initially available during the hydration process. The tests will need to be conducted using mortar and, eventually, concrete to check their applicability to more realistic structures. Admixtures and reinforcing fibers will need to be introduced to future specimens to see what effect, if any, they have on the material's piezoelectric properties. 


\section{Bibliography}

[1] B. Dawson, "Vibration condition monitoring techniques for rotating machinery," The Shock and Vibration Digest vol. 8, p. 3, 1976.

[2] F. J. Holler, D. A. Skoog, and S. R. Crouch, Principles of Instrumental Analysis: Cengage Learning, 2007.

[3] G. Gautschi, Piezoelectric Sensorics: Force, Strain, Pressure, Acceleration and Acoustic Emission Sensors, Materials and Amplifiers. Germany: Springer, 2002.

[4] S. Wen and D. Chung, "Piezoelectric cement-based materials with large coupling and voltage coefficients," Cement and Concrete Research, vol. 32, pp. 335-339, 2002.

[5] ASTM, "Standard Specification for Portland Cement," vol. C150, ed. PA: ASTM, 2009.

[6] A. Neville, Properties of Concrete, Fourth ed. New York, N.Y.: John Wiley \& Sons, Inc., 1997.

[7] I. Soroka, Portland Cement Paste and Concrete. New York, N.Y.: Chemical Publishing Co., Inc., 1980.

[8] H. Taylor, The Chemistry of Cements. London: Academic Press, 1964.

[9] G. Park, H. Sohn, C. R. Farrar, and D. J. Inman, "Overview of Piezoelectric ImpedanceBased Health Monitoring and Path forward," The Shock and Vibration Digest, vol. 35, pp. 451-463, 2003.

[10] L. Cartz, Nondestructive Testing: Radiography, Ultrasonics, Liquid Penetrant, Magnetic Particle, Eddy Current: Asm International, 1995.

[11] J. Krautkramer and H. Krautkramer, Ultrasonic Testing of Materials. Germany: SpringerVerlag, 1990.

[12] I. Viktorov, Rayleigh and Lamb waves: physical theory and applications: Plenum Press, 1970.

[13] J. Duke, Acousto-ultrasonics: theory and application: Plenum Press, 1988.

[14] Y. Lange, "Characteristics of the impedance method of inspection and of impedance inspection transducers," Russian journal of nondestructive testing, vol. 14, pp. 958-966, 1978.

[15] P. Cawley, "The impedance method of non-destructive inspection," NDT International, vol. 17, pp. 59-65, 1984.

[16] V. Giurgiutiu and A. Zagrai, "Characterization of piezoelectric wafer active sensors," Journal of Intelligent Material Systems and Structures, vol. 11, pp. 959-976, 2000. 